Quantitative Political Economy Research Group

Department of Political Economy

King's College London

\title{
QPE
}

\section{Calamities, Common Interests, Shared Identity: What Shapes Altruism and Reciprocity?}

QPE Working Paper 2021-31

\author{
Cevat Giray Aksoy \\ Antonio Cabrales \\ Mathias Dolls \\ Ruben Durante \\ Lisa Windsteiger
}

May 22, 2021 


\title{
Calamities, Common Interests, Shared Identity: What Shapes Altruism and Reciprocity?
}

\author{
Cevat Giray Aksoy, Antonio Cabrales, Mathias Dolls, \\ Ruben Durante, Lisa Windsteiger*
}

May 21, 2021

\begin{abstract}
We conduct a large-scale survey experiment in nine European countries to study how priming a major crisis (COVID-19), common economic interests, and a shared identity influences altruism, reciprocity and trust of EU citizens. We find that priming the COVID-19 pandemic increases altruism and reciprocity towards compatriots, citizens of other EU countries, and nonEU citizens. Priming common European values also boosts altruism and reciprocity but only towards compatriots and fellow Europeans. Priming common economic interests has no tangible impact on behaviour. Trust in others is not affected by any treatment. Our results are consistent with the parochial altruism hypothesis, which asserts that because altruism arises out of inter-group conflict, humans show a tendency to favor members of their own groups.
\end{abstract}

Keywords: COVID-19, Europe, altruism, reciprocity, survey experiment JEL-Codes: D72, H51, H53, H55, O52, P52

Ethics clearance: Ethics Office, King's College London, MRA-19/20-2010

Pre-registration: AEARCTR-0006164

\footnotetext{
*Aksoy: European Bank for Reconstruction and Development, King's College London and IZA (aksoyc@ebrd.com); Cabrales: Universidad Carlos III de Madrid (antonio.cabrales@uc3m. es); Dolls: ifo Institute, CESifo, IZA and ZEW (dolls@ifo.de); Durante: ICREA, UPF, IPEG, Barcelona School of Economics, and CEPR (ruben.durante@upf .edu); Windsteiger: Max Planck Institute for Tax Law and Public Finance (lisa.windsteiger@tax.mpg.de). We thank Ralph De Haas and participants of the EconPol Europe Annual Conference, the CESifo Area Conference on Public Economics, Experimental Economics Seminar at New York University and the Workshop on Perceptions and Policy Preferences for helpful comments and suggestions. Pablo Zarate provided excellent research assistance. The views presented are those of the authors and not necessarily of the EBRD or any other institution.
} 


\section{Introduction}

The evolution of altruism is one of the most studied phenomena in both natural (Nowak et al. 2010) and social sciences (Kurzban et al. 2015). One of the key theories to explain altruism in humans involves group competition (Bowles 2006). Importantly, the theory predicts that this competition-driven altruism will be intensified in critical events, such as wars, and that it is not directed universally towards all members of the species but that it is "parochial" in nature (Choi and Bowles 2007). ${ }^{1}$ This means that altruism is more likely to be triggered if those affected by a catastrophe share elements of the potential donor's identity. ${ }^{2}$ In this work we causally identify factors that enhance trust, reciprocity and altruism towards other individuals in society. In particular, we are interested in whether critical periods and a sense of "group belonging" induce people to display otherregarding preferences.

Previous evidence on this topic is rather mixed. Fisman et al. (2015), for example, compare Dictator game donations before and after the Great Recession and find that donations went down. Meer et al. (2017) also find that charitable donations decreased in the Great Recession in ways that are not explained by changes in income and health. And yet, Kalogeraki (2018) finds that in Greece "Since 2008 there has been a great proliferation of civil society initiatives traced in the plethora of social solidarity networks that aim to help vulnerable social groups to cope with the detrimental effects of the crisis." Also, Hartman and Morse (2020) show that exposure to violence in the Liberian civil war makes individuals more likely to "host a higher proportion of non-coethnic, non-coreligious and distressed refugees" in the Ivorian refugee crisis. In terms of identity, Bernhard et al. (2006) show that thirdparty altruistic punishment is more common for own group members, Yamagishi and Mifune (2008) show that dictators need to know the recipients share group membership to enhance their generosity, and Vázquez et al. (2017) show that sharing a sense of identity fosters altruism in twins. ${ }^{3}$

\footnotetext{
${ }^{1}$ The robustness of this conclusion is debated in Dyble (2021).

${ }^{2}$ This can sometimes lead to paradoxical results. Bernhard et al. (2006) show that because ingroup members are punished less often for norm violations by the ingroup, the group suffers from more norm violations.

${ }^{3}$ Other studies have documented how historical experiences of cooperation (or conflict) in the face of adversities or external threats can have a persistent impact on social preferences and social capital (Nunn and Wantchekon 2011; Guiso, Sapienza, and Zingales 2016; Buggle and Durante 2021).
} 
Our paper contributes to this literature by exploring several factors affecting generosity simultaneously in a context where causality can be more properly attributed, and working with a representative sample of individuals from very diverse countries in Europe.

Specifically, we present novel evidence from a large incentivized survey experiment on how trust, reciprocity, and altruism are affected by a major health crisis (COVID-19), common economic interests (EU trade), and shared values (EU ideals). We also study how the effect varies depending on whether these attitudes are directed at individuals from the same country, citizens of other European countries, and non-EU citizens. We conducted the survey in August 2020 in nine European countries where the impact of the pandemic was considerably different: France, Germany, Greece, Hungary, Italy, the Netherlands, Poland, Spain, and Sweden. ${ }^{4}$

The survey was organized as follows. Participants were randomly assigned into one of three treatments or a control group. All groups were first asked a question about a social or economic phenomenon, and were then given information about it. In Treatment 1 (COVID-19) subjects were asked and told about the impact of the pandemic, in terms of total deaths per million people, in their own country relative to the EU as a whole. In Treatment 2 (EU Trade) participants were asked and informed about their country's share of exports going to other EU countries. Treatment 3 (EU Values) discussed what share of respondents in the Eurobarometer survey across all EU countries mentioned peace, democracy, protection of human rights or equality as fundamental and highly representative of the European project. Finally, participants in the control group were asked and informed about a neutral fact, in this case, the population density of their country.

After the treatment phase, subjects participated in two standard incentivized games: the Dictator game and the Trust game. ${ }^{5}$ The goal is to assess how the decisions of individuals exposed to the different treatments (COVID-19, EU trade, EU values) - which are still present in their mind - differ from those in the control group.

The Dictator game aims to measure generosity towards others. Each player is

\footnotetext{
${ }^{4}$ The survey was also fielded in two non-EU countries (Turkey and Serbia). However, this paper solely focuses on the survey experiments conducted in the EU countries.

${ }^{5}$ These games are incentivized since subjects know that their remuneration - beyond the fee they receive for completing the survey - depends on their own decisions and those of the players they are matched with.
} 
given 200 points and is asked to choose how much to transfer to another randomly matched participant. In our experiment the sender is asked to choose the size of the transfer for three different cases: if the recipient is from the same country, from another EU country, or from a non-EU country. Crucially, since the receiver makes no decision, the sender's choice reflects unconditional altruism rather than reciprocity.

The Trust game also involves a sender and a receiver. The sender is assigned 100 points and decides between: i) sending 50 points to the receiver and keeping 50 points for themselves, ii) sending 200 points to the receiver who then chooses how many points (between 0 and 150) to return to the sender. From the perspective of the sender, the second option is riskier, since they only receive a payment if the receiver sends back points. However, it is potentially more profitable since the total points to be split between the two players are twice as large. The decision of the sender measures their level of trust that the other player will not behave opportunistically. The decision of the receiver reflects, instead, their level of reciprocity towards someone who has behaved nicely towards them. As in the dictator game, participants are allowed to make different choices depending on the country of origin of the other player (same, other EU, non-EU).

After the games, participants were asked various questions about their political orientation, the strength of their European identity, their level of income, and the evolution of the latter during the pandemic.

It is important to note that the treatments we propose are rather mild, and simply prime certain information which is likely already present in the respondent's mind. ${ }^{6}$ Hence, in the absence of other ethical ways to induce a major crisis or an identity shock, our experiment provides a clean way to estimate the causal effect of these aspects on trust, reciprocity and altruism, which arguably represents the lower bound of the true effect.

Our results can be summarized as follows. We find that priming the COVID-19 crisis (T1) has a positive effect on both altruism (that is, the sender's choice in the Dictator game) and reciprocity (that is, the receiver's choice in the Trust game). The effect is sizeable (between $2 \%$ and $3 \%$ ) and statistically significant regardless of the country of the other party, though generally larger for compatriots (for reciprocity

\footnotetext{
${ }^{6}$ Other papers use similar priming techniques to investigate various aspects of the COVID-19 pandemic. See for instance Daniele et al. (2020) and Bartos et al. (2020). Alesina et al. (2018) use priming to investigate the effect of immigration on demand for redistribution.
} 
and altruism) and fellow EU citizens (for altruism), than for non-EU citizens.

Priming European common values (T3) also has a significant impact on both reciprocity and altruism, but only towards respondents of the same country and of other EU countries. Interestingly, the effect on altruism is very similar for compatriots and other EU citizens. This patterns confirms that, indeed, the values primed in this treatment are perceived as common to EU citizens rather than universal.

Priming EU trade relations (T2) has a limited impact on all three outcomes, and only displays marginally significant effects on reciprocity towards compatriots (positive) and altruism towards non-EU citizens (negative). Finally, we find respondents' trust in others (that is, the sender's choice in the Trust game) to be unaffected by any of the treatments, with all coefficients being precisely estimated zeros.

These results are consistent with the parochial altruism hypothesis: a major crisis and a shared identity boost altruism and reciprocity in general but more intensely for closer groups. The lack of effect on trust suggests the effect comes from enhanced empathy towards others, and not by the expectation that they will behave better.

Finally, we examine how our treatment effects vary depending on the characteristics of the respondents and of their place of residence. To refine our search, we use a causal forest methodology (Wager and Athey 2018). Six variables emerge as most relevant from this approach: i) the strength of European identity, ii) the incidence of COVID-19 cases in the region, iii) the economic effect of COVID-19 on the household, iv) household income in February 2020 (pre-pandemic), v) age, and vi) political orientation. We then replicate our baseline econometric analysis including interaction terms between our treatments and each of the above-mentioned variables. Three of them appear to be important in mediating the effect of our treatments: regional incidence of COVID-19, economic impact of COVID-19 on the household, and political orientation.

In particular, the heterogeneity of results for the priming of COVID-19 (T1) indicate that the positive effect of the treatment on altruism is stronger for individuals that were economically hit by the pandemic, who are more generous towards people both within and outside the EU. At the same time, when COVID-19 is primed, these same individuals display less trust in fellow citizens. This could be a reaction to perceived lack of support by the community. Along the same lines, 
we find that, for individuals from regions heavily affected by the pandemic, T1 has a significant negative effect on trust, this time directed towards non-EU citizens. Finally, regarding the mediating role of political orientation, we find that the priming of COVID-19 has a stronger positive effect on trust, reciprocity, and altruism for right-leaning respondents. However, these effects are only (marginally) significant for attitudes towards citizens of the same country, consistent with these individuals identifying strongly with their national community. We find similar heterogeneity in results for T2 and T3. Overall, given the large number of potential dimensions of heterogeneity, it is reasonable to conclude that our treatment effects are, to a large extent, homogeneous.

The remainder of the paper is organized as follows. In Section 2 we present the survey, the experimental design, including the Trust and the Dictator game, and the descriptive statistics. In section 3 we discuss the empirical strategy, and in section 4 we present the results. Section 5 concludes.

\section{Survey Design and Descriptive Statistics}

\subsection{Data collection and the survey structure}

We conducted large-scale surveys in nine EU member countries (France, Germany, Greece, Hungary, Italy, Netherlands, Poland, Spain, Sweden) and in two nonEU countries (Serbia, Turkey) in early August 2020. The surveys were designed using an online platform and the survey participation links were distributed by the professional survey company Respondi. ${ }^{7}$ The samples were aimed to be broadly representative with respect to age, gender and sub-national region and with a good spread across income classes. We designed the original questionnaire in English, which was then translated into the major conversational languages of each country by professional translators. To ensure the quality of translations, an independent third party with knowledge of the survey also reviewed and revised the translation as necessary.

In terms of recruitment of respondents, the professional survey company sent out survey links via email to its pool of respondents. Emails informed potential participants about the length and non-commercial nature of the survey, but they

${ }^{7}$ https://www.respondi.com/EN/ 
were not told about the topic. Participation was voluntary and once respondents agreed to take part in the survey they were directed to the consent page and asked some initial screening questions that ensured that the quotas for age, gender and subnational region were met. All respondents in our sample fully completed the survey and received a baseline remuneration of about 2 Euros and an extra payment, which was based on their decisions made in the Trust and Dictator games. The average time for completion of the survey was about 20 minutes.

Our survey consisted of four blocks: (i) initial screening questions on sociodemographic characteristics; (ii) random split of respondents into four groups (three treatment groups and one control group); (iii) Trust and Dictator games; and (iv) other questions used for the heterogeneity analysis (such as strength of European identity, political preferences, economic impact of COVID-19 on the respondent's household). ${ }^{8}$

We adopted common practices to enhance data quality: (i) Following other papers relying on online surveys (Prescott et al. 2016; Barrero et al. 2021), we clean our data by dropping respondents in the bottom $10 \%$ of the survey time distribution. These respondents completed the survey in half of the expected time which makes it unlikely that questions were considered carefully. ${ }^{9}$ (ii) Throughout the survey, we randomized the answer options to prevent order bias, which might arise when all respondents view the answer options in the same order. Our final sample includes 25,720 respondents (about 2,800-3,100 participants per EU country) between 18 and 70 years of age. ${ }^{10}$

\subsection{Experimental design and the information treatments}

After the first set of screening questions on socio-demographic characteristics, respondents were randomly assigned into four different groups in each of the nine

\footnotetext{
${ }^{8}$ The main questionnaire can be found here.

${ }^{9}$ We implemented an attention check at the end of the survey where respondents were asked whether they could recall the information presented in our treatments. We find that respondents in the bottom $10 \%$ of the survey time distribution are much less likely to recall the presented information. The correlation between the time spent on the survey and the result of the attention check ( 1 if respondents answered correctly, 0 otherwise) is positive and significant for the full sample, but becomes insignificant once those who completed the survey speedily are dropped. It is reassuring, however, that our results are mostly unaffected by the sample selection.

${ }^{10}$ As explained below, respondents in the two non-EU countries participated in the Trust and Dictator games but received different information treatments and outcome questions whose analysis is not part of this paper.
} 
EU member country samples. We refer to the first sub-sample as the COVID-19 treatment group (T1), to the second as the EU Trade treatment group (T2) and to the third as the EU Common Values treatment group (T3). The fourth sub-sample is the control group. All sub-samples contain about 700-750 survey respondents per country.

We designed our experiments to study how various information treatments affect behavior in the Trust and Dictator games. The respondents received the following information treatments:

1. COVID-19 treatment group (T1): Respondents were told that the COVID-19 pandemic is causing large-scale loss of life and severe human suffering. Next, they were asked whether they think that the number of confirmed COVID-19 deaths per million people in their country by July 1, 2020, was higher, lower or around the same as in the EU as a whole.

2. EU Trade treatment group (T2): Respondents were informed that exports of goods within the EU have substantially increased in recent decades as economic integration within the EU's internal market has intensified. Next, they were asked what share of exports from their country they thought went to other EU countries in 2019.

3. EU Common Values treatment group (T3): Respondents were told that according to a recent Eurobarometer survey, European citizens consider the following values as fundamental and highly representative of the European project: peace, democracy, protection of human rights and equality. They were then asked about what share of respondents across all EU countries they believed had mentioned at least one of these values as fundamental and highly representative of the European project.

After answering the respective question, respondents in all three treatment groups were told the correct answer. In particular, they were provided with information on the COVID-19 death toll per capita in their country and in the EU (T1), the export share in EU trade in their country (T2), and the share of Eurobarometer respondents across all EU countries agreeing on the most frequently mentioned common values in the EU (T3).

Respondents in the control group were informed about a neutral fact that would not be expected to influence any of their later answers in the survey: we 
asked them to guess their country's population density in 2019 and then informed them of the correct number.

\subsection{Our outcome measures for trust, reciprocity, and altru- ism}

After providing respondents with the respective information treatments described above, the survey continued with the Trust game and the Dictator game which were played in a random order.

Each game was played between two players (Player A and Player B), and participants were informed that they were randomly matched with another survey respondent who could either be from their own country, from another EU country or from a non-EU country. They had to take decisions both as Player A and Player $\mathrm{B}$ in the Trust game and as Player A in the Dictator game, and for each of the three possible matches (fellow player from own country / another EU country / non-EU country), respectively. Respondents were not informed if they were actually matched with a person from their own country, from another EU country or from a non-EU country. $^{11}$

The order of the three decision situations was randomized. Respondents were also told that - depending on their own decisions and those of their counterpart in the game - they could earn points (that is, remuneration) determined by the points they earned in the selected game. After the survey was completed in all countries, we randomly matched participants in pairs ${ }^{12}$ and randomly decided which one is Player A and which one is Player B. This process determined the pay-out from the relevant game for each respondent. ${ }^{13}$

In both games, players took decisions, which determined the allocation of points between themselves and their counterpart. In the Trust game, Player A had to decide between two options:

\footnotetext{
${ }^{11}$ To avoid stereotypes affecting respondents' selections in the two games, we also did not inform them which EU or non-EU countries their fellow player could potentially come from.

${ }^{12}$ Matched pairs are either "respondent's country - respondent's country", "respondent's country another EU country", or "respondent's country - non-EU country".

${ }^{13}$ Respondents were paid in their local currency. 100 points earned in the selected game correspond to 1 EUR. The average pay-out in our sample amounts to 0.85 EUR. This is not a large amount, but Camerer and Hogarth (1999) show for games as ours that behavior is not sensitive to the size of experimental incentives.
} 
1. Option A1: By choosing this option, Player A allocated 50 points to themselves and 50 points to Player B.

2. Option A2: This option handed over the decision to Player B, who received 200 points and could decide how many points to keep for themselves, and how many points to allocate to Player A. Player B had to keep a minimum of 50 points for themselves so that any number between 0 and 150 points could be allocated to Player A. By choosing this option, Player A could potentially increase their own payoff, but only if they trusted in Player B to return more than 50 points to them.

All respondents were also asked to make selections as Player B in the Trust game for the case that Player A would choose option A2. In the Dictator game, Player A got 200 points and decided how much to keep for themselves and how much to allocate to Player B. Player B did not make any active decisions in this game. Player A could theoretically keep all the points for themselves.

After getting the full schedule of allocations, we construct our main outcome variables based on the following definitions:

Trust: We consider the choice of option A2 by Player A as a sign of trust towards their counterpart. Our outcome variable for trust takes a value of 1 if the Player A chose option A2 and zero otherwise.

Reciprocity: We consider Player B's decision as reciprocal if they returned more than 50 points to Player A. Our outcome variable for reciprocity ranges between 0 to 150 points.

Altruism: Any positive amount of points that Player A allocated to Player B in the Dictator game is interpreted as a sign of altruism, with the degree of altruism increasing with the number of points. Our outcome variable for altruism ranges between 0 to 200 .

\subsection{Additional data}

We employ data from the Joint Research Centre of the European Commission on the cumulative regional COVID-19 case incidence at the NUTS-2 level by 31 July 2020. As we elicited the NUTS-2 region respondents are living in, we are able to merge the regional COVID-19 incidence to our survey data. These data are used in the heterogeneity analysis (Section 4.2). 


\subsection{Descriptive statistics}

\section{Balance}

Appendix Table A1 shows socio-demographic characteristics of the survey respondents in the three treatment groups and the control group. A formal balancing test revealing that each sub-sample is balanced along observable respondent characteristics is presented in Section 4.3.

\section{Initial beliefs}

As mentioned above, before informing respondents about the COVID-19 death toll (T1), their country's export share in EU trade (T2) and the agreement among European citizens on shared values in the EU (T3), we elicited their prior beliefs about these numbers. On one hand, this was done to increase the treatment effect (if people are asked about an issue first and have to guess a number, it can generally be expected that they think more about said issue than if they are simply presented with information) but on the other hand it also helps us pinpoint whether our treatments were (predominantly) "positive" or "negative" (depending on how beliefs were corrected on average).

Appendix Table A2 reports the share of respondents in the three treatment groups whose beliefs elicited prior to the information treatment were correct as well as the share of respondents underestimating or overestimating the numbers. ${ }^{14}$ In the COVID-19 treatment group, 13\% (31\%) of respondents wrongly believe that the per capita COVID-19 death toll in their country by July 1, 2020, was higher (lower) than in the EU. The information treatment therefore moves their beliefs downwards (upwards). $47 \%$ of respondents answer the question on the incidence of confirmed COVID-19 deaths in their country relative to the EU average correctly. Both in the EU trade (66\%) and the EU common values treatment group (52\%), the majority of respondents underestimate the correct values, that is, their beliefs about the importance of the EU internal market for their country's exports and about the share of European citizens who agree on the most important common values in the EU are moved upwards. A fifth (T2) and roughly a quarter (T3) of respondents

\footnotetext{
${ }^{14}$ For respondents in the EU Trade (T2) and the EU Common Values (T3) treatment groups who were asked to provide a percentage, we define a correct answer as not deviating more than +/5 percentage points from the correct value. Note that the "Don't know" answer option was only available for respondents in the COVID-19 treatment group.
} 
overestimate the correct values and only relatively few respondents provide correct answers.

As initial beliefs for EU trade integration and common values were below the truth for the majority of respondents, the average treatment effects can be regarded as displaying the results of (on average) an upwards correction concerning these beliefs. It can thus be argued that treatments T2 and T3 were on average "positive" (pro EU) treatments. ${ }^{15}$ On the other hand, T1 was certainly not a generally positive or optimistic treatment - in fact it was probably rather pessimistic on average, irrespective of where countries stood in terms of COVID-19 affectedness compared to the rest of the EU, because it put the COVID-19 pandemic with all its ensuing problems front and centre in respondents' minds.

Appendix Tables A3-A5 report country-specific statistics on the beliefs elicited prior to the information treatments. As shown in Table A3, Germany, Greece, Hungary, and Poland are the four EU countries in our sample which had a COVID19 death toll below the EU average by July 1, 2020, while the number of COVID-19 deaths was above the EU average in France, Italy, the Netherlands, Spain and Sweden. In the former group of countries, most respondents estimated correctly that their countries' death toll per capita was below EU average (except for Poland, where people were split roughly half and half in their prior beliefs). On the other hand, respondents in the latter group mostly underestimated their countries' death toll compared to EU average in all countries except Spain. Table A4 reveals that in respondents' beliefs about the importance of EU trade for their country varies a lot across different countries. While in Germany and Sweden, for example, the share of respondents who over- and underestimate the export share in EU trade is relatively similar, respectively, the majority of respondents underestimate the true value in the other EU countries in our sample. In contrast, the agreement on common values in the EU (Table A5) is underestimated by the majority of respondents in all nine EU countries in our sample.

\section{Outcome variables}

Appendix Tables A6-A8 provide summary statistics for the selections made in the Trust game and the Dictator game. Appendix Table A6 presents the share of respon-

${ }^{15}$ At least concerning T3 this is a relatively uncontroversial claim. Concerning T2, it could be argued that for those respondents who do not regard EU trade integration as beneficial, the treatment is not necessarily positive. 
dents in the three treatment groups (T1-T3) and the control group choosing option A1 and A2 as Player A in the Trust game if the fellow player is from respondent's country, from another EU country and from a non-EU country, respectively. In the full sample, option A1 (A2) is chosen by $59-60 \%$ (40-41\%) of the respondents (see column "Total"). There are relatively small differences in the shares across the four sub-groups (T1-T3 and control group) and depending on whether the fellow player is from the respondent's own country, another EU country or from a non-EU country.

As Player B in the Trust game, the average number of points returned to Player A amounts to 84-87 as shown in column 5 of Table A7. Differences across sub-groups are somewhat more pronounced than for Player A in the Trust game and, as one might expect, the degree of reciprocity is highest (lowest) if the fellow player is from the respondent's own country (a non-EU country).

In the Dictator game (Table A8), the average number of points Player A sends to Player B ranges from 98-105 points (column 5). It is higher in T1 and T3 as compared to T2. As for Player B in the Trust game, mean values are highest (lowest) if the fellow player is from the respondent's own country (a non-EU country).

Appendix Tables A9-A11 show descriptive statistics for our outcome variables trust, reciprocity and altruism by country. ${ }^{16}$ There are some notable differences across countries. The share of respondents who show trust towards their fellow players by choosing option A2 as Player A in the Trust game is highest in Hungary, the Netherlands and Sweden. France, Hungary, and Spain are the countries where respondents on average reveal the highest level of reciprocity, while the level of altruism is on average highest in Italy and Hungary.

\section{Empirical Strategy}

We use OLS models to estimate the average treatment effects for ease of interpretation, though logit regression models returned similar patterns. Our models take the following form:

$$
Y_{i}=\beta T_{i}+\gamma X_{i}+\mu_{c}+\varsigma_{t}+\epsilon_{i}
$$

\footnotetext{
${ }^{16}$ The tables show shares, the mean and its standard deviation for respondents in the control group.
} 
where $Y_{i}$ measures the allocations made by respondents in the Trust and Dictator game. The treatment dummies $T_{i}$ capture the effect of the randomized information treatments presented above. Given that the information treatments are randomized and therefore independent of all other relevant variables, their effects can be interpreted in a causal manner.

$X_{i}$ is a vector of control variables that includes age, gender, marital status, education, equivalized household gross income in February/July 2020, total number of children and adults younger/older than 65 in the household, as well as the time to complete survey. In all models, we include country fixed effects, $\mu_{c}$, (to control for time-invariant variation in the outcome variables caused by factors that vary across countries) and date fixed effects, $\varsigma_{t}$, (to capture the impact of country-level shocks that affect all countries simultaneously). ${ }^{17}$ We report robust standard errors, $\epsilon_{i}$.

\section{Results}

\subsection{Average treatment effects}

This section presents average treatment effects of the COVID-19 treatment (T1), the EU trade treatment (T2), and the EU common values treatment (T3) on interpersonal trust, reciprocity and altruism while heterogeneous treatment effects are presented in Section 4.2. As described in Section 2, after the randomized information treatments, all respondents continued the survey by playing the Trust and Dictator game in random order, both as Player A and B in the Trust game and as Player A in the Dictator game. We interpret the selection of option A2 as Player A in the Trust game as trusting behavior. Reciprocity (altruism) is measured by the number of points Player B in the Trust game (Player A in the Dictator game) allocated to their fellow player.

We present average treatment effects on our main outcomes (trust, reciprocity and altruism) in Table 1 separately for whether the fellow player was from the respondents' own country, another EU country or a non-EU country. When it comes to trust, we find that none of our treatments has a significant effect on the selections made by respondents as Player A in the Trust game on average. ${ }^{18}$ Looking

\footnotetext{
${ }^{17}$ All our results hold when excluding these covariates (regression tables available upon request).

${ }^{18}$ Table A12 in the Appendix reveals that logit regressions yield the same result. As shown in Section 4.2 , there are heterogeneous treatment effects on trust though which cancel out on average.
} 
at reciprocity, we find that both the COVID-19 treatment (T1) and the EU common values treatment (T3) lead to more reciprocal behavior if respondents assume the fellow player to be from their own country. In this case, respondents in T1 and T3 send on average 2 points more to Player A compared to respondents in the control group. The treatment effect corresponds to roughly $2 \%$ of the average number of points respondents in the control group send back to Player A. Moreover, we find positive albeit somewhat smaller treatment effects for $\mathrm{T} 3$ if the fellow player is from another EU country and for T1 if the fellow player is from a non-EU country. The average treatment effect is weakly significant for T1 if the fellow player is assumed to be from another EU country and for T2 if the fellow player is assumed to be from the respondent's own country. Apart from the latter, the EU trade treatment (T2) does not lead to significant differences in behavior compared to the control group.

Finally, we find that both the COVID-19 treatment (T1) and the EU common values treatment (T3) significantly increase respondents' altruism if they make their selection under the assumption that their fellow player is a citizen of their own country or a citizen of another EU member state. Moreover, T1 also leads to a higher level of altruism if the fellow player is assumed to be from a non-EU country. On average, these treatment effects amount to 2-3 points which corresponds to $2-3 \%$ of the average number of points respondents in the control group send to their fellow players. Again, only one of the average treatment effects of the EU trade treatment (T2) is weakly significant. Respondents in T2 allocate fewer points to Player B if the selection is made under the assumption that the fellow player is from a non-EU country. 
Table 1: Average treatment effects: Trust, Reciprocity, Altruism

\begin{tabular}{|c|c|c|c|c|c|c|c|c|c|}
\hline & \multicolumn{3}{|c|}{ Outcome: Trust } & \multicolumn{3}{|c|}{ Outcome: Reciprocity } & \multicolumn{3}{|c|}{ Outcome: Altruism } \\
\hline & Own country & $\mathrm{EU}$ & Non EU & Own country & $\mathrm{EU}$ & Non EU & Own country & $\mathrm{EU}$ & Non EU \\
\hline \multirow[t]{2}{*}{ T1: COVID-19 } & -0.000 & -0.001 & 0.004 & $2.108^{* * *}$ & $1.049^{*}$ & $1.318^{* *}$ & $2.958^{* * *}$ & $2.874^{* * *}$ & $1.788^{* *}$ \\
\hline & $(0.009)$ & $(0.009)$ & $(0.009)$ & $(0.609)$ & $(0.604)$ & $(0.618)$ & $(0.826)$ & $(0.817)$ & $(0.839)$ \\
\hline \multirow[t]{2}{*}{ T2: EU Trade } & -0.005 & 0.002 & -0.010 & $1.142^{*}$ & 0.157 & -0.072 & -0.268 & 0.334 & $-1.539^{*}$ \\
\hline & $(0.009)$ & $(0.009)$ & $(0.009)$ & $(0.602)$ & $(0.599)$ & $(0.614)$ & $(0.819)$ & $(0.804)$ & $(0.828)$ \\
\hline \multirow[t]{2}{*}{ T3: EU Common values } & 0.001 & 0.004 & -0.001 & $2.212^{* * *}$ & $1.410^{* *}$ & 0.798 & $2.261^{* * *}$ & $2.595^{* * *}$ & 1.032 \\
\hline & $(0.009)$ & $(0.009)$ & $(0.009)$ & $(0.595)$ & $(0.590)$ & $(0.607)$ & $(0.804)$ & $(0.788)$ & $(0.819)$ \\
\hline Observations & 25720 & 25720 & 25720 & 25720 & 25720 & 25720 & 25720 & 25720 & 25720 \\
\hline$R^{2}$ & 0.017 & 0.018 & 0.016 & 0.010 & 0.011 & 0.010 & 0.018 & 0.018 & 0.015 \\
\hline Fixed effects: & \multicolumn{3}{|c|}{ Country \& date } & \multicolumn{3}{|c|}{ Country \& date } & \multicolumn{3}{|c|}{ Country \& date } \\
\hline
\end{tabular}

Notes: OLS model. Robust standard errors are in parentheses: ${ }^{*} p<0.10,{ }^{* *} p<0.05,{ }^{* * *} p<0.01$. Controls: age, gender, marital status, education level, equivalized household gross income in February/July 2020, time to complete survey, total number of children and adults younger/older than 65 in the household.

Figures A1-A3 in the Appendix present average treatment effects at the country level. As shown in Figure A1, the null finding for the effect on trust holds across all nine EU countries in our sample. If anything, the EU common values treatment reduces trust towards fellow players from non-EU countries in Italy and Sweden. For the effect on reciprocity (Figure A2), we find particularly strong effects from the COVID-19 treatment (T1) in Spain, where reciprocity is positively affected, irrespective of the fellow player being from the respondent's country, another EU country or from a non-EU country. In a similar vein, the EU common values treatment (T3) leads to higher reciprocity in particular in France, Poland, and Spain if the fellow player is from the respondent's own country or from another EU country. For the effect on altruism (Figure A3), T1 and T3 lead to strongest upward shifts in France and Spain. ${ }^{19}$

\footnotetext{
${ }^{19}$ After the games we also collected information about the respondent's evaluation of how their national government managed the pandemic, and trust in their government. In this regard, we find that priming the pandemic (T1) led to a significant decline in respondents' trust in the government, though only in countries where the death toll due to COVID-19 was higher (that is, above EU average). These additional results, available upon request, support the view that, due to poor management of the pandemic, citizens' perception of the competence of policy makers worsened, fueling disenchantment and distrust in institutions.
} 


\subsection{Heterogeneity analysis}

\subsubsection{Selection of variables}

We also look beyond the average treatment effects to understand how the causal effects vary with observable characteristics. To select the variables along which to explore treatment heterogeneity, and later on also to identify (potentially non-linear) heterogeneous treatment effects (that is, variation in the direction and magnitude of treatment effects for individuals within a population), we use Causal Forests methodology, which provides a data-driven, less selective framework for heterogeneous treatment estimation (Athey and Imbens 2016; Athey et al. 2019).

In particular, we build regression trees that systematically split the control variable space into increasingly smaller subsets and aim to predict an outcome variable by building on the observations with similar characteristics. When a variable has very little predictive power, it is assigned a negative importance score, which is essentially equivalent to low importance for treatment heterogeneity. Overall, Causal Forest estimation combines a magnitude of regression trees to identify treatment effects, where each tree is defined by different orders and subsets of covariates.

We consider our three information treatments for heterogeneity, namely T1: COVID-19, T2: Trade and T3: EU Common Values and feed the Causal Forest algorithm the full set of control variables defined in Section 3 as well as attitudinal variables (EU identity, political orientation), indicators for economic and health vulnerability in the COVID-19 pandemic (economic effect of COVID-19 on the respondent's household, per capita number of confirmed COVID-19 cases in the respondent's sub-region, whether respondent has a suspected COVID-19 infection) and additional socio-demographic characteristics (religion, urban residency). ${ }^{20}$ Our model takes the following form:

$$
\widetilde{Y_{i c t}}=\alpha_{i}\left(X_{i t}^{\prime}\right)+\tau_{i}\left(X_{i t}^{\prime}\right) T_{i}+u_{i c t}
$$

\footnotetext{
${ }^{20}$ As we elicit respondents' political orientation and EU identity only after our treatments, these variables could theoretically be affected by them. Using them as controls or for heterogeneity analysis could thus pose endogeneity problems. However, as Table A14 shows, both variables do not seem to be significantly affected by any of our treatments. We thus consider their inclusion in our analyses as valid.
} 
where $\widetilde{Y_{i c t}}$ is a summary index, ${ }^{21}$ which is constructed based on points allocated in Trust and Dictator games, of respondent $i$ in county $c$ and survey date $t$, and $X_{i t}^{\prime}$ includes the list of variables described above. ${ }^{22}$

Appendix Figures A4, A5, and A6 present the variable importance results for the fellow player being from (a) the respondent's own country, (b) another EU country, and (c) a non-EU country. ${ }^{23}$ We consistently find that the following six dimensions have the highest predictive power for our outcome variables: (i) respondent's age; (ii) household equivalized income quintile in February, 2020; (iii) per capita number of confirmed COVID-19 cases in the respondent's sub-region; (iv) political orientation (in terms of left-right spectrum); (v) economic effect of the COVID-19 pandemic on the respondent's household (not at all, just a little, a fair amount, and a great deal), and (vi) EU identity (ranging from not feeling a citizen of EU to feeling a citizen of $E U$ only). Therefore, we only focus on these dimensions in the following analyses.

\subsubsection{Heterogeneous treatment effects: interpersonal trust, reciprocity, altruism}

We present the results from standard OLS regressions including interactions of the above variables (which have been identified as important for treatment heterogeneity via Causal Forest). Tables 2 to 4 show these results for regional COVID-19 case incidence, economic effect of COVID-19 on the respondent's household and political orientation. The regressions include the same set of control variables as before in the analysis of average treatment effects and, additionally, the interacted variables as well as interaction terms between the treatment dummies and country dummies, education, and gender, respectively. The latter interaction terms are included to

${ }^{21}$ For each individual, we calculate the index score as follows: points allocated in the Dictator game + points allocated in the Trust game as Player B +100 points if the choice in the Trust game as Player A was A2 (and zero points otherwise).

${ }^{22}$ For the sake of clarity and space, we don't show the variable importance graphs for each outcome separately. The variable importance results considering outcomes separately return similar patterns and are available upon request.

${ }^{23}$ Appendix Figures A4-A6 simplify the visualization of the control variables by reporting aggregates. For example, the indicator "education level" includes the respective education dummies (primary, secondary, tertiary) and describes how often one of the education dummies is used to split the estimation sample in Causal Forests. Note also that we do not report the country fixed effects and date fixed effects (although they are included in our Causal Forest models) in variable importance graphs since our main purpose is to understand which individual observable characteristics are important for treatment heterogeneity. 
make sure that the interaction terms of interest included in Tables $2-4$ are not driven by single countries or the educational level or gender of respondents. We performed the same analysis also for age, income and EU identity, but as we did not find any significant interaction effects we report these regression tables only in the Appendix (see Tables A15 to A17).

One key result that emerges from Tables 2 to 4 is that respondents who were economically affected by the COVID-19 crisis are less trusting. The estimated coefficient terms are negative for $\mathrm{T} 1$ and $\mathrm{T} 3$, but only significantly different from zero concerning trust towards fellow natives in T1, and towards non-EU citizens in T3. On the other hand, these people are more altruistic in T1 and T2. The effects are significant at conventional levels and rather high for altruism towards other EU citizens and towards non-EU citizens. There is no corresponding effect concerning altruism in T3, the estimated interaction effects are even negative (though not significant). Reciprocity doesn't seem to vary with respondents' economic affectedness in any treatment group.

Respondents living in a region with higher COVID-19 case incidence seem to be less trusting, in particular towards EU and non-EU citizens, in every treatment group. However, the effects are only significant for trust towards non-EU citizens in $\mathrm{T} 1$ and towards other EU citizens in T2. They seem to be more reciprocal in all treatments, though the effects are small and only statistically significant for reciprocity towards fellow natives and non-EU citizens in T2 and towards EU and non-EU citizens in T3. Altruism doesn't seem to be affected by regional incidence in any of our treatments.

Respondents who describe themselves as politically right-wing seem to be more trusting, reciprocal and altruistic towards fellow nationals in all our treatment groups, with significant interaction effects for all three outcomes if primed with COVID-19, and also if primed with EU Common values in the case of trust and with EU Trade in the case of reciprocity.

We also checked the existence of non-linear treatment effects, for example by looking at different age or income groups, or by differentiating between respondents who live in regions with high vs. low COVID-19 incidence, who have low vs. high EU identity or who are at the left vs. right end of the political spectrum. By and large, results do not change much when we account for the possibility of non-linear 
Table 2: Heterogeneity analysis - Trust

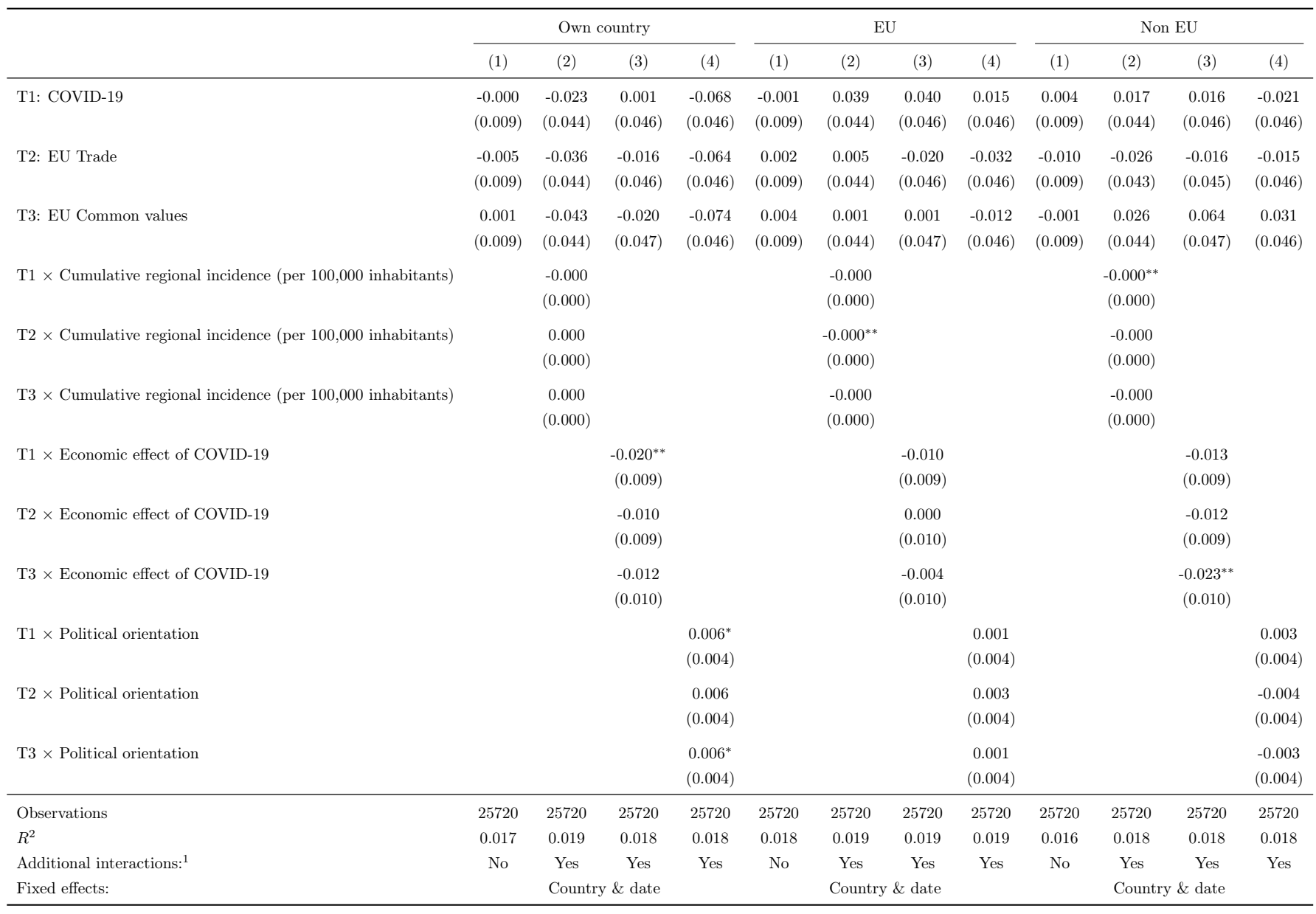

Notes: OLS model. Robust standard errors are in parentheses: ${ }^{*} p<0.10,{ }^{* *} p<0.05,{ }^{* * *} p<0.01$. Controls: age, gender, marital status, education level, equivalized household gross income in February/July 2020, time to complete survey, total number of children and adults younger/older than 65 in the household and the interacted variable. ${ }^{1}$ The OLS regressions also include interactions between the treatment dummies and country dummies, education, and gender, respectively.

${ }^{24}$ Results are available upon request. 
Table 3: Heterogeneity analysis - Reciprocity

\begin{tabular}{|c|c|c|c|c|c|c|c|c|c|c|c|c|}
\hline & \multicolumn{4}{|c|}{ Own country } & \multicolumn{4}{|c|}{$\mathrm{EU}$} & \multicolumn{4}{|c|}{ Non EU } \\
\hline & (1) & (2) & (3) & (4) & (1) & (2) & (3) & (4) & (1) & (2) & (3) & (4) \\
\hline T1: COVID-19 & $\begin{array}{c}2.108^{* * * *} \\
(0.609)\end{array}$ & $\begin{array}{c}0.733 \\
(3.183)\end{array}$ & $\begin{array}{c}1.237 \\
(3.350)\end{array}$ & $\begin{array}{l}-1.191 \\
(3.347)\end{array}$ & $\begin{array}{l}1.049^{*} \\
(0.604)\end{array}$ & $\begin{array}{c}3.141 \\
(3.203)\end{array}$ & $\begin{array}{c}2.438 \\
(3.345)\end{array}$ & $\begin{array}{c}3.071 \\
(3.375)\end{array}$ & $\begin{array}{l}1.318^{* *} \\
(0.618)\end{array}$ & $\begin{array}{c}0.771 \\
(3.223)\end{array}$ & $\begin{array}{c}1.843 \\
(3.382)\end{array}$ & $\begin{array}{c}1.357 \\
(3.397)\end{array}$ \\
\hline T2: EU Trade & $\begin{array}{l}1.142^{*} \\
(0.602)\end{array}$ & $\begin{array}{c}-5.865^{*} \\
(3.153)\end{array}$ & $\begin{array}{l}-5.379 \\
(3.273)\end{array}$ & $\begin{array}{c}-7.003^{* *} \\
(3.311)\end{array}$ & $\begin{array}{c}0.157 \\
(0.599)\end{array}$ & $\begin{array}{c}-3.392 \\
(3.212)\end{array}$ & $\begin{array}{l}-3.815 \\
(3.339)\end{array}$ & $\begin{array}{l}-2.674 \\
(3.364)\end{array}$ & $\begin{array}{l}-0.072 \\
(0.614)\end{array}$ & $\begin{array}{l}-3.815 \\
(3.250)\end{array}$ & $\begin{array}{c}-2.898 \\
(3.378)\end{array}$ & $\begin{array}{l}-0.424 \\
(3.419)\end{array}$ \\
\hline T3: EU Common values & $\begin{array}{c}2.212^{* * *} \\
(0.595)\end{array}$ & $\begin{array}{l}-2.052 \\
(3.217)\end{array}$ & $\begin{array}{c}-0.236 \\
(3.394)\end{array}$ & $\begin{array}{l}-2.374 \\
(3.354)\end{array}$ & $\begin{array}{l}1.410^{* *} \\
(0.590)\end{array}$ & $\begin{array}{c}-3.806 \\
(3.201)\end{array}$ & $\begin{array}{l}-2.498 \\
(3.378)\end{array}$ & $\begin{array}{l}-3.707 \\
(3.345)\end{array}$ & $\begin{array}{c}0.798 \\
(0.607)\end{array}$ & $\begin{array}{l}-4.374 \\
(3.254)\end{array}$ & $\begin{array}{l}-2.489 \\
(3.419)\end{array}$ & $\begin{array}{l}-3.397 \\
(3.389)\end{array}$ \\
\hline T1 $\times$ Cumulative regional incidence (per 100,000 inhabitants) & & $\begin{array}{c}0.002 \\
(0.003)\end{array}$ & & & & $\begin{array}{c}0.004 \\
(0.003)\end{array}$ & & & & $\begin{array}{l}0.005^{*} \\
(0.003)\end{array}$ & & \\
\hline T2 $\times$ Cumulative regional incidence (per 100,000 inhabitants) & & $\begin{array}{c}0.006^{* *} \\
(0.003)\end{array}$ & & & & $\begin{array}{c}0.004 \\
(0.003)\end{array}$ & & & & $\begin{array}{c}0.006^{* *} \\
(0.003)\end{array}$ & & \\
\hline T3 $\times$ Cumulative regional incidence (per 100,000 inhabitants) & & $\begin{array}{l}0.005^{*} \\
(0.003)\end{array}$ & & & & $\begin{array}{c}0.007^{* *} \\
(0.003)\end{array}$ & & & & $\begin{array}{c}0.007^{* *} \\
(0.003)\end{array}$ & & \\
\hline $\mathrm{T} 2 \times$ Economic effect of COVID-19 & & & $\begin{array}{c}0.581 \\
(0.683)\end{array}$ & & & & $\begin{array}{c}0.854 \\
(0.675)\end{array}$ & & & & $\begin{array}{c}0.331 \\
(0.686)\end{array}$ & \\
\hline T3 $\times$ Economic effect of COVID-19 & & & $\begin{array}{c}-0.202 \\
(0.691)\end{array}$ & & & & $\begin{array}{c}0.313 \\
(0.681)\end{array}$ & & & & $\begin{array}{c}-0.030 \\
(0.692)\end{array}$ & \\
\hline $\mathrm{T} 1 \times$ Political orientation & & & & $\begin{array}{l}0.520^{*} \\
(0.269)\end{array}$ & & & & $\begin{array}{c}0.236 \\
(0.265)\end{array}$ & & & & $\begin{array}{c}0.157 \\
(0.272)\end{array}$ \\
\hline $\mathrm{T} 2 \times$ Political orientation & & & & $\begin{array}{c}0.555^{* *} \\
(0.267)\end{array}$ & & & & $\begin{array}{c}0.111 \\
(0.264)\end{array}$ & & & & $\begin{array}{c}-0.346 \\
(0.270)\end{array}$ \\
\hline T3 $\times$ Political orientation & & & & $\begin{array}{c}0.333 \\
(0.262)\end{array}$ & & & & $\begin{array}{c}0.335 \\
(0.258)\end{array}$ & & & & $\begin{array}{c}0.131 \\
(0.264)\end{array}$ \\
\hline Observations & 25720 & 25720 & 25720 & 25720 & 25720 & 25720 & 25720 & 25720 & 25720 & 25720 & 25720 & 25720 \\
\hline$R^{2}$ & 0.010 & 0.013 & 0.013 & 0.013 & 0.011 & 0.013 & 0.013 & 0.015 & 0.010 & 0.012 & 0.012 & 0.015 \\
\hline
\end{tabular}

Notes: OLS model. Robust standard errors are in parentheses: ${ }^{*} p<0.10,{ }^{* *} p<0.05,{ }^{* * *} p<0.01$. Controls: age, gender, marital status, education level, equivalized household gross income in February/July 2020, time to complete survey, total number of children and adults younger/older than 65 in the household and the interacted variable. ${ }^{1}$ The OLS regressions also include interactions between the treatment dummies and country dummies, education, and gender, respectively. 
Table 4: Heterogeneity analysis - Altruism

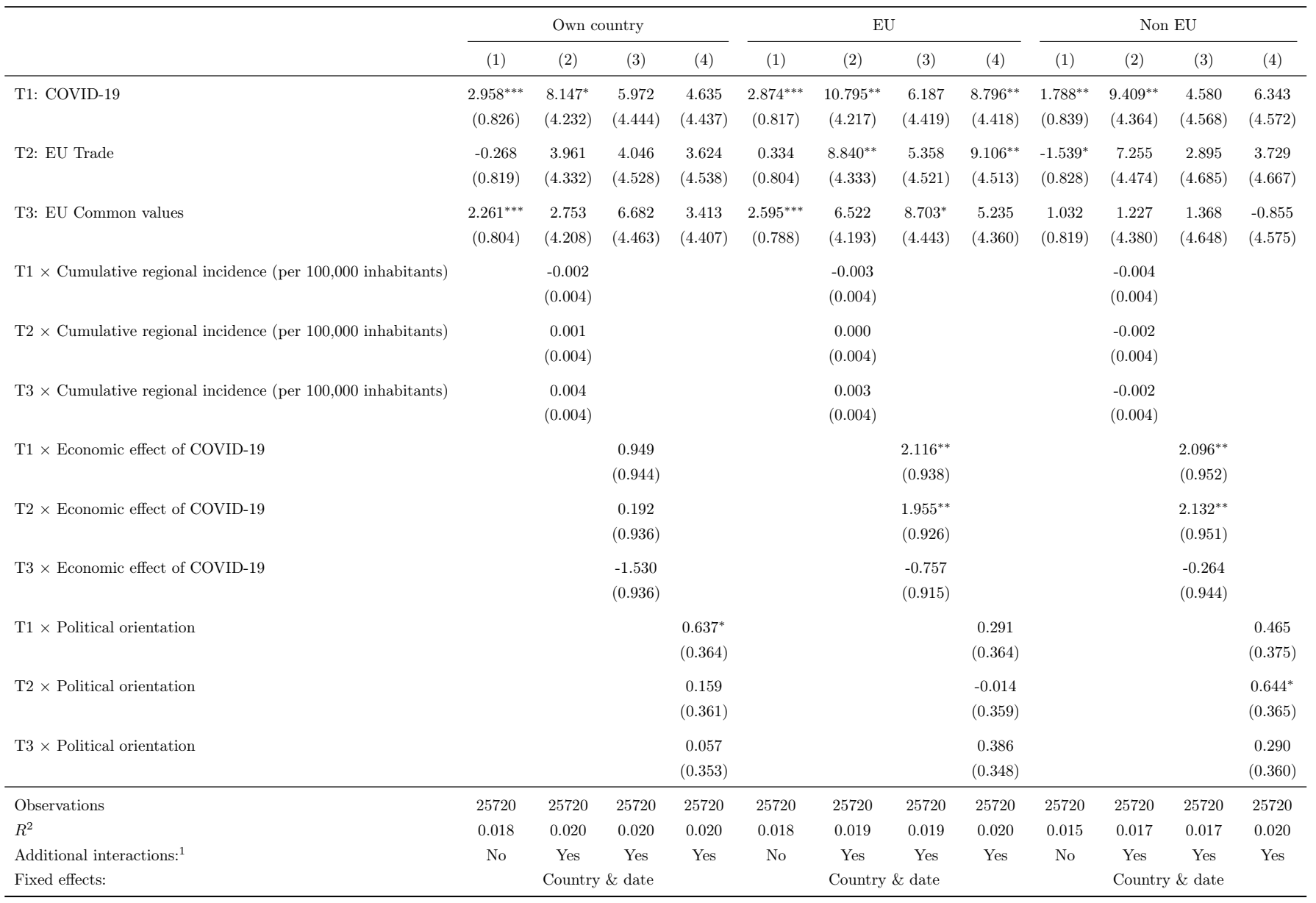

Notes: OLS model. Robust standard errors are in parentheses: ${ }^{*} p<0.10,{ }^{* *} p<0.05,{ }^{* * *} p<0.01$. Controls: age, gender, marital status, education level, equivalized household gross income in February/July 2020, time to complete survey, total number of children and adults younger/older than 65 in the household and the interacted variable. ${ }^{1}$ The OLS regressions also include interactions between the treatment dummies and country dummies, education, and gender, respectively.

\subsection{Robustness checks}

\section{Balancing tests}

The main identifying assumption of our analysis is that the randomization of our information treatments worked properly. Therefore, we compute differences in mean values of key socio-demographic characteristics as well as the mean time to complete the survey between the three treatment groups and the control group, respectively, and test for their statistical significance. As can be seen in Table A13 
in the Appendix, most of the differences are insignificant or only weakly significant suggesting that the randomization worked well. Respondents in the EU trade treatment group (T2) completed the survey somewhat faster than respondents in the control group. However, time differences are small which suggests that our information treatments do not differ in their complexity.

\section{Excluding one country at a time}

In Figures A7-A9 in the Appendix, we estimate average treatment effects of T1-T3 on trust, reciprocity and altruism, but exclude one country at a time in order to examine to what extent our results are driven by specific countries. The first estimate in each panel (dark blue line) is based on the full sample and refers to the baseline result (cf. Table 1), while the following estimates show how the baseline result changes when one country at a time is excluded. Our baseline result for trust holds for all sample variations. The average treatment effect of the COVID-19 treatment (T1) (the EU common values treatment (T3)) on reciprocity lose some significance for fellow players from other EU countries when Spain, France or Germany (T1) (Spain or Poland (T3)) are excluded from the sample. The significant effect of T1 and T3 on altruism remains significant when single countries are excluded.

\section{Concluding Remarks}

Altruism, reciprocity and social trust are important determinants for prosperity and a well-functioning society. Our paper provides causal evidence on how common crises (in particular the COVID-19 crisis), common economic interests and common values affect these qualities among European citizens. We ran an incentivized survey experiment in nine EU (eleven European) countries in early August 2020. Our treatment groups were primed with their country's COVID-19 death toll relative to the EU average, with their country's degree of EU trade integration and with commonly held European values, respectively, while the control group received neutral information unlikely to affect their actions and responses later in the survey. Afterwards, survey respondents played the Trust and Dictator games, where they could earn an extra payment depending on their decisions and the decisions of their matched player, who could be either a fellow citizen, a respondent from another EU country or a citizen from a non-EU country. Subsequently, they answered a set 
of attitudinal questions also related to their personal experience of the COVID-19 pandemic.

We show that the common crisis and the common values treatment have the strongest effects, in particular on altruism and reciprocity towards fellow natives and other EU citizens. Interpersonal trust is not affected on average. Priming respondents with a common economic interest, on the other hand, doesn't have much effect on any of our three main outcome variables.

Our results are consistent with the parochial altruism hypothesis that a crisis or shared identity can enhance altruism, in particular for closer groups. In addition, we show that reciprocity tends to work in a similar way. Interpersonal trust, on the other hand, seems to be a more stable quality, less easily affected by our priming treatments. A shared economic interest doesn't have a significant impact on altruism or reciprocity, neither towards fellow natives nor towards other EU or non-EU citizens. This result suggests that economic interests alone do not suffice to build social cohesion and unity. 


\section{References}

Alesina, A., A. Miano, and S. Stantcheva (2018). Immigration and redistribution. NBER Working Paper 24733.

Athey, S. and G. Imbens (2016). Recursive partitioning for heterogeneous causal effects. Proceedings of the National Academy of Sciences 113(27), 7353-7360.

Athey, S., J. Tibshirani, and S. Wager (2019). Generalized random forests. The Annals of Statistics $47(2), 1148-1178$.

Barrero, J. M., N. Bloom, and S. J. Davis (2021). Why Working From Home Will Stick. Stanford mimeo.

Bartos, V., M. Bauer, J. Cahlíková, and J. Chytilová (2020). Covid-19 crisis fuels hostility against foreigners. CESifo Working Paper No. 8309.

Bernhard, H., E. Fehr, and U. Fischbacher (2006). Group affiliation and altruistic norm enforcement. American Economic Review 96(2), 217-221.

Bernhard, H., U. Fischbacher, and E. Fehr (2006). Parochial altruism in humans. Nature (London) 442(7105), 912-915.

Bowles, S. (2006). Group competition, reproductive leveling, and the evolution of human altruism. science 314(5805), 1569-1572.

Buggle, J. C. and R. Durante (2021, 01). Climate Risk, Cooperation and the Co-Evolution of Culture and Institutions. The Economic Journal. ueaa127.

Camerer, C. F. and R. M. Hogarth (1999). The effects of financial incentives in experiments: A review and capital-labor-production framework. Journal of risk and uncertainty 19(1), 7-42.

Choi, J.-K. and S. Bowles (2007). The coevolution of parochial altruism and war. science 318(5850), 636-640.

Daniele, G., A. F. Martinangeli, F. Passarelli, W. Sas, and L. Windsteiger (2020). Wind of Change? Experimental Survey Evidence on the COVID-19 Shock and Socio-Political Attitudes in Europe. Working Paper of the Max Planck Institute for Tax Law and Public Finance No. 2020-10.

Dyble, M. (2021). The evolution of altruism through war is highly sensitive to population structure and to civilian and fighter mortality. Proceedings of the National Academy of Sciences 118(11). 
Fisman, R., P. Jakiela, and S. Kariv (2015). How did distributional preferences change during the great recession? Journal of Public Economics 128, 84-95.

Guiso, L., P. Sapienza, and L. Zingales (2016). Long-term persistence. Journal of the European Economic Association 14(6), 1401-1436.

Hartman, A. C. and B. S. Morse (2020). Violence, empathy and altruism: Evidence from the ivorian refugee crisis in liberia. British Journal of Political Science 50(2), 731-755.

Kalogeraki, S. (2018). Experiences of the economic crisis: Volunteering in social solidarity networks during the recession in greece. In Citizens and the Crisis, pp. 165-186. Springer.

Kurzban, R., M. N. Burton-Chellew, and S. A. West (2015). The evolution of altruism in humans. Annual review of psychology 66, 575-599.

Meer, J., D. Miller, and E. Wulfsberg (2017). The great recession and charitable giving. Applied Economics Letters 24(21), 1542-1549.

Nowak, M. A., C. E. Tarnita, and E. O. Wilson (2010). The evolution of eusociality. Nature 466(7310), 1057-1062.

Nunn, N. and L. Wantchekon (2011). The slave trade and the origins of mistrust in africa. American Economic Review 101(7), 3221-52.

Prescott, J., N. D. Bishara, and E. Starr (2016). Understanding noncompetition agreements: the 2014 noncompete survey project. Michigan State Law Review, 369-464.

Vázquez, A., Á. Gómez, J. R. Ordoñana, W. B. Swann, and H. Whitehouse (2017). Sharing genes fosters identity fusion and altruism. Self and Identity 16(6), 684-702.

Wager, S. and S. Athey (2018). Estimation and inference of heterogeneous treatment effects using random forests. Journal of the American Statistical Association 113(523), 1228-1242.

Yamagishi, T. and N. Mifune (2008). Does shared group membership promote altruism? fear, greed, and reputation. Rationality and Society 20(1), 5-30. 


\section{A Appendix Tables}

Table A1: Balance table

\begin{tabular}{|c|c|c|c|c|}
\hline & $\begin{array}{c}(1) \\
\text { T1: Covid } \\
\text { Mean/SE }\end{array}$ & $\begin{array}{c}(2) \\
\text { T2: EU Trade } \\
\text { Mean/SE }\end{array}$ & $\begin{array}{c}(3) \\
\text { T3: EU Common values } \\
\text { Mean } / \mathrm{SE}\end{array}$ & $\begin{array}{c}(4) \\
\text { Control } \\
\text { Mean/SE }\end{array}$ \\
\hline Age & $\begin{array}{c}43.218 \\
(0.175)\end{array}$ & $\begin{array}{c}42.977 \\
(0.176)\end{array}$ & $\begin{array}{c}43.074 \\
(0.176)\end{array}$ & $\begin{array}{r}42.746 \\
(0.176)\end{array}$ \\
\hline Female & $\begin{array}{c}0.543 \\
(0.006)\end{array}$ & $\begin{array}{c}0.548 \\
(0.006)\end{array}$ & $\begin{array}{c}0.551 \\
(0.006)\end{array}$ & $\begin{array}{c}0.538 \\
(0.006)\end{array}$ \\
\hline Other gender & $\begin{array}{c}0.001 \\
(0.000)\end{array}$ & $\begin{array}{c}0.001 \\
(0.000)\end{array}$ & $\begin{array}{c}0.001 \\
(0.000)\end{array}$ & $\begin{array}{c}0.001 \\
(0.000)\end{array}$ \\
\hline Secondary education & $\begin{array}{c}0.486 \\
(0.006)\end{array}$ & $\begin{array}{c}0.484 \\
(0.006)\end{array}$ & $\begin{array}{c}0.481 \\
(0.006)\end{array}$ & $\begin{array}{c}0.485 \\
(0.006)\end{array}$ \\
\hline Tertiary education & $\begin{array}{c}0.452 \\
(0.006)\end{array}$ & $\begin{array}{c}0.450 \\
(0.006)\end{array}$ & $\begin{array}{c}0.457 \\
(0.006)\end{array}$ & $\begin{array}{c}0.453 \\
(0.006)\end{array}$ \\
\hline Single & $\begin{array}{c}0.369 \\
(0.006)\end{array}$ & $\begin{array}{c}0.380 \\
(0.006)\end{array}$ & $\begin{array}{c}0.379 \\
(0.006)\end{array}$ & $\begin{array}{c}0.388 \\
(0.006)\end{array}$ \\
\hline $\mathrm{N}^{\circ}$ adults above 65 in the household & $\begin{array}{c}0.268 \\
(0.008)\end{array}$ & $\begin{array}{c}0.261 \\
(0.008)\end{array}$ & $\begin{array}{c}0.268 \\
(0.008)\end{array}$ & $\begin{array}{c}0.262 \\
(0.008)\end{array}$ \\
\hline $\mathrm{N}^{\circ}$ adults below 65 in the household & $\begin{array}{c}1.969 \\
(0.013)\end{array}$ & $\begin{array}{c}2.012 \\
(0.013)\end{array}$ & $\begin{array}{c}1.995 \\
(0.013)\end{array}$ & $\begin{array}{c}2.000 \\
(0.013)\end{array}$ \\
\hline $\mathrm{N}^{\circ}$ children in the household & $\begin{array}{c}0.466 \\
(0.010)\end{array}$ & $\begin{array}{c}0.469 \\
(0.011)\end{array}$ & $\begin{array}{c}0.452 \\
(0.010)\end{array}$ & $\begin{array}{c}0.471 \\
(0.010)\end{array}$ \\
\hline Hh. Equivalized Gross Income Quintile (Feb. 2020) & $\begin{array}{c}1.967 \\
(0.017)\end{array}$ & $\begin{array}{c}1.921 \\
(0.018)\end{array}$ & $\begin{array}{c}1.958 \\
(0.018)\end{array}$ & $\begin{array}{c}1.939 \\
(0.018)\end{array}$ \\
\hline Hh. Equivalized Gross Income Quintile (July 2020) & $\begin{array}{c}1.953 \\
(0.017)\end{array}$ & $\begin{array}{c}1.908 \\
(0.018)\end{array}$ & $\begin{array}{c}1.955 \\
(0.018)\end{array}$ & $\begin{array}{c}1.923 \\
(0.018)\end{array}$ \\
\hline COVID-19 regional incidence & $\begin{array}{c}305.065 \\
(4.059)\end{array}$ & $\begin{array}{c}296.358 \\
(4.040)\end{array}$ & $\begin{array}{l}299.751 \\
(4.012)\end{array}$ & $\begin{array}{c}302.134 \\
(4.078)\end{array}$ \\
\hline EU identity & $\begin{array}{c}5.553 \\
(0.036)\end{array}$ & $\begin{array}{c}5.557 \\
(0.036)\end{array}$ & $\begin{array}{c}5.598 \\
(0.036)\end{array}$ & $\begin{array}{c}5.537 \\
(0.036)\end{array}$ \\
\hline Political orientation & $\begin{array}{c}4.977 \\
(0.030)\end{array}$ & $\begin{array}{c}4.958 \\
(0.030)\end{array}$ & $\begin{array}{c}4.945 \\
(0.030)\end{array}$ & $\begin{array}{c}4.927 \\
(0.030)\end{array}$ \\
\hline Economic effect of COVID-19 & $\begin{array}{c}2.211 \\
(0.012)\end{array}$ & $\begin{array}{c}2.220 \\
(0.012)\end{array}$ & $\begin{array}{c}2.197 \\
(0.012)\end{array}$ & $\begin{array}{c}2.196 \\
(0.012)\end{array}$ \\
\hline Time to complete the survey & $\begin{array}{l}22.059 \\
(0.179)\end{array}$ & $\begin{array}{l}21.405 \\
(0.171)\end{array}$ & $\begin{array}{l}21.894 \\
(0.186)\end{array}$ & $\begin{array}{l}21.955 \\
(0.193)\end{array}$ \\
\hline $\mathrm{N}$ & 6512 & 6353 & 6468 & 6387 \\
\hline
\end{tabular}

Notes: Mean (standard deviation). 
Table A2: Beliefs (T1-T3)

\begin{tabular}{lrrrrr}
\hline & \multicolumn{5}{c}{ Treatment groups } \\
& T1 & T2 & T3 & Total & N \\
& Col\% & Col\% & Col\% & Col\% & \\
\hline Answer correctly & 47 & 13 & 21 & 27 & 5,244 \\
Underestimate & 31 & 66 & 52 & 50 & 9,615 \\
Overestimate & 13 & 20 & 27 & 20 & 3,885 \\
Don't know & 9 & 0 & 0 & 3 & 589 \\
Total & 100 & 100 & 100 & 100 & 19,333 \\
\hline
\end{tabular}

Notes: The table reports the share of respondents in the three treatment groups whose belief elicited before the information was correct and the share of respondents who underestimated/overestimated the correct numbers. For $\mathrm{T} 2$ and $\mathrm{T} 3$, answers are counted as correct if the given percentage does not deviate more than $+/-5$ percentage points from the correct value. Only respondents in T1 had the option to choose the "Don't know" answer option.

Table A3: COVID-19 beliefs (T1)

\begin{tabular}{|c|c|c|c|c|c|c|c|c|c|c|c|}
\hline \multirow[b]{2}{*}{ Treatment intensity } & \multicolumn{4}{|c|}{ Below EU average } & \multicolumn{5}{|c|}{ Above EU average } & \multirow[b]{2}{*}{$\begin{array}{l}\text { Total } \\
\text { Col\% }\end{array}$} & \multirow[b]{2}{*}{$\mathbf{N}$} \\
\hline & $\begin{array}{l}\text { DE } \\
\text { Col\% }\end{array}$ & $\begin{array}{c}\text { EL } \\
\text { Col\% }\end{array}$ & $\begin{array}{l}\text { HU } \\
\mathrm{Col} \%\end{array}$ & $\begin{array}{l}\text { PL } \\
\text { Col\% }\end{array}$ & $\begin{array}{c}\text { ES } \\
\mathrm{Col} \%\end{array}$ & $\begin{array}{l}\text { FR } \\
\mathrm{Col} \%\end{array}$ & $\begin{array}{c}\text { IT } \\
\text { Col\% }\end{array}$ & $\begin{array}{l}\text { NL } \\
\mathrm{Col} \%\end{array}$ & $\begin{array}{c}\text { SE } \\
\text { Col\% }\end{array}$ & & \\
\hline Answer correctly & 77 & 74 & 58 & 44 & 55 & 20 & 28 & 25 & 40 & 47 & 3,045 \\
\hline Underestimate & - & - & - & - & 35 & 67 & 59 & 67 & 51 & 31 & 2,020 \\
\hline Overestimate & 19 & 22 & 33 & 45 & - & - & - & - & - & 13 & 858 \\
\hline Don’t know & 5 & 4 & 9 & 11 & 10 & 13 & 13 & 8 & 9 & 9 & 589 \\
\hline Total & 100 & 100 & 100 & 100 & 100 & 100 & 100 & 100 & 100 & 100 & 6,512 \\
\hline
\end{tabular}

Notes: The table reports answer shares for the question: "Do you think the number of confirmed COVID-19 deaths (per million people) in [respondent's country] by July 1, 2020, is higher or lower than the number of confirmed COVID-19 deaths (per million people) in the EU as a whole?" Countries listed in columns "Below EU average" (DE, EL, HU, PL) had a COVID-19 death toll below the EU average by July 1, 2020. Countries listed in columns "Above EU average" (ES, FR, IT, NL, SE) had a COVID-19 death toll above the EU average by July 1, 2020. 
Table A4: Trade beliefs (T2)

\begin{tabular}{|c|c|c|c|c|c|c|c|c|c|c|c|}
\hline & \multicolumn{9}{|c|}{ Country } & \multirow{3}{*}{$\begin{array}{l}\text { Total } \\
\text { Col } \%\end{array}$} & \multirow{3}{*}{$\mathbf{N}$} \\
\hline & $\mathrm{DE}$ & EL & ES & FR & HU & IT & NL & $\mathbf{P L}$ & $\mathrm{SE}$ & & \\
\hline & $\mathrm{Col} \%$ & $\mathrm{Col} \%$ & $\mathrm{Col} \%$ & $\mathrm{Col} \%$ & $\mathrm{Col} \%$ & $\mathrm{Col} \%$ & $\mathrm{Col} \%$ & $\mathrm{Col} \%$ & $\mathrm{Col} \%$ & & \\
\hline Answer correctly & 14 & 11 & 12 & 11 & 13 & 14 & 24 & 5 & 15 & 13 & 833 \\
\hline Underestimate & 40 & 68 & 78 & 70 & 84 & 63 & 59 & 91 & 42 & 66 & 4,220 \\
\hline Overestimate & 46 & 21 & 10 & 20 & 3 & 23 & 16 & 4 & 43 & 20 & 1,300 \\
\hline Total & 100 & 100 & 100 & 100 & 100 & 100 & 100 & 100 & 100 & 100 & 6,353 \\
\hline
\end{tabular}

Notes: The table reports answer shares for the question: "What is your best guess about what share of [respondent's country's] exports went to other EU countries in 2019?". Answer correctly for respondents whose answer is $+/-5$ percentage points from the correct value.

Table A5: EU Common values beliefs (T3)

\begin{tabular}{|c|c|c|c|c|c|c|c|c|c|c|c|}
\hline & \multicolumn{9}{|c|}{ Country } & \multirow{3}{*}{$\begin{array}{l}\text { Total } \\
\text { Col } \%\end{array}$} & \multirow{3}{*}{$\mathbf{N}$} \\
\hline & $\mathrm{DE}$ & EL & ES & FR & HU & IT & NL & PL & SE & & \\
\hline & $\mathrm{Col} \%$ & $\mathrm{Col} \%$ & $\mathrm{Col} \%$ & $\mathrm{Col} \%$ & $\mathrm{Col} \%$ & $\mathrm{Col} \%$ & $\mathrm{Col} \%$ & $\mathrm{Col} \%$ & $\mathrm{Col} \%$ & & \\
\hline Answer correctly & 23 & 23 & 18 & 20 & 26 & 18 & 27 & 18 & 17 & 21 & 1,366 \\
\hline Underestimate & 46 & 47 & 55 & 62 & 46 & 62 & 47 & 57 & 48 & 52 & 3,375 \\
\hline Overestimate & 31 & 30 & 27 & 18 & 28 & 20 & 26 & 25 & 34 & 27 & 1,727 \\
\hline Total & 100 & 100 & 100 & 100 & 100 & 100 & 100 & 100 & 100 & 100 & 6,468 \\
\hline
\end{tabular}

Notes: The table reports answer shares for the question: "In your opinion, what share of respondents across all EU countries mentioned at least one of these values [peace, democracy, protection of human rights and equality] as fundamental and highly representative of the European project?". Answer correctly for respondents whose answer is $+/-5$ percentage points from the correct value. 
Table A6: Trust game: Descriptive Statistics Player A

\begin{tabular}{lrrrrrrr}
\hline & \multicolumn{7}{c}{ Treatment groups } \\
& T1 & T2 & T3 & Control & Total & N \\
\cline { 2 - 4 } & Col\% & Col\% & Col\% & Col\% & Col\% & \\
\hline Own country & & & & & & \\
A1 & 59.1 & 59.7 & 59.2 & 59.1 & 59.3 & 15,242 \\
A2 & 40.9 & 40.3 & 40.8 & 40.9 & 40.7 & 10,478 \\
Total & 100.0 & 100.0 & 100.0 & 100.0 & 100.0 & 25,720 \\
\hline EU country & & & & & & \\
A1 & 59.4 & 59.2 & 59.0 & 59.2 & 59.2 & 15,228 \\
A2 & 40.6 & 40.8 & 41.0 & 40.8 & 40.8 & 10,492 \\
Total & 100.0 & 100.0 & 100.0 & 100.0 & 100.0 & 25,720 \\
\hline Non-EU country & & & & & & \\
A1 & 59.1 & 60.6 & 59.6 & 59.4 & 59.7 & 15,356 \\
A2 & 40.9 & 39.4 & 40.4 & 40.6 & 40.3 & 10,364 \\
Total & 100.0 & 100.0 & 100.0 & 100.0 & 100.0 & 25,720 \\
\hline
\end{tabular}

Notes: The table reports the share of respondents in the three treatment groups (T1-T3) and the control group who have selected option A1 and A2 as Player A in the Trust game, depending on whether the fellow player is from their own country, another EU country or from a non-EU country. 
Table A7: Trust game: Descriptive Statistics Player B

\begin{tabular}{lccccc}
\hline & $(1)$ & $(2)$ & $(3)$ & $(4)$ & $(5)$ \\
& $\mathrm{T} 1$ & $\mathrm{~T} 2$ & $\mathrm{~T} 3$ & Control & Total \\
Variable & Mean/SD & Mean/SD & Mean/SD & Mean/SD & Mean/SD \\
\hline \multirow{2}{*}{ Own country } & 87.258 & 86.259 & 87.379 & 85.142 & 86.516 \\
& $(35.070)$ & $(33.771)$ & $(33.350)$ & $(34.257)$ & $(34.131)$ \\
EU country & 85.883 & 84.948 & 86.237 & 84.788 & 85.469 \\
& $(35.080)$ & $(34.048)$ & $(33.357)$ & $(33.774)$ & $(34.077)$ \\
Non-EU country & 85.211 & 83.788 & 84.700 & 83.877 & 84.400 \\
& $(35.730)$ & $(34.634)$ & $(34.212)$ & $(34.735)$ & $(34.838)$ \\
$\mathrm{N}$ & 6512 & 6353 & 6468 & 6387 & 25720 \\
\hline
\end{tabular}

Notes: The table reports the average number of points and its standard deviation respondents in the three treatment groups (T1-T3) and the control group have returned to the sender (Player A) as Player B in the Trust game, depending on whether the fellow player is from their own country, another EU country or from a non-EU country.

Table A8: Dictator game: Descriptive Statistics Player A

\begin{tabular}{lccccc}
\hline & & & & & $(4)$ \\
& & $(2)$ & $(3)$ & $(5)$ \\
Variable & Mean/SD & Mean/SD & Mean/SD & Mean/SD & Mean/SD \\
\hline \multirow{2}{*}{ Own country } & 106.551 & 103.416 & 105.821 & 103.567 & 104.852 \\
& $(47.936)$ & $(46.426)$ & $(45.137)$ & $(46.509)$ & $(46.533)$ \\
EU country & 102.397 & 99.999 & 102.161 & 99.552 & 101.039 \\
& $(47.599)$ & $(45.332)$ & $(43.998)$ & $(45.886)$ & $(45.741)$ \\
Non-EU country & 99.559 & 96.360 & 98.849 & 97.794 & 98.152 \\
& $(48.570)$ & $(46.476)$ & $(46.110)$ & $(47.331)$ & $(47.149)$ \\
N & 6512 & 6353 & 6468 & 6387 & 25720 \\
\hline
\end{tabular}

Notes: The table reports the average number of points and its standard deviation respondents in the three treatment groups (T1-T3) and the control group have sent to the receiver (Player B) as Player A in the Dictator game, depending on whether the fellow player is from their own country, another EU country or from a non-EU country. 
Table A9: Trust game: Descriptive Statistics Player A by country

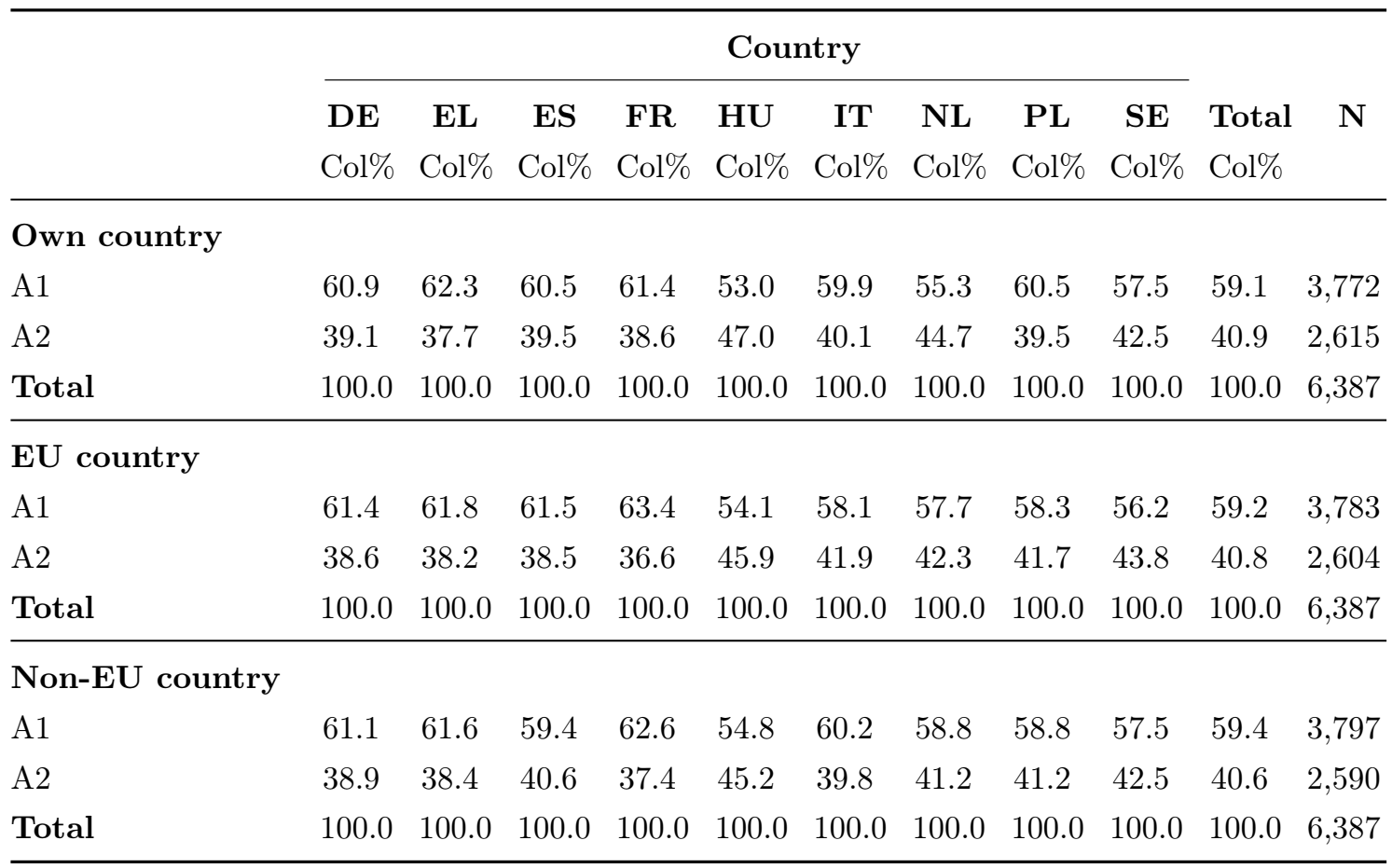

Notes: The table reports the share of respondents in the control group by country who have selected option A1 and A2 as Player A in the Trust game, depending on whether the fellow player is from their own country, another EU country or from a non-EU country.

Table A10: Trust game: Descriptive Statistics Player B by country

\begin{tabular}{lccccccccc}
\hline & $(1)$ & $(2)$ & $(3)$ & $(4)$ & $(5)$ & $(6)$ & $(7)$ & $(8)$ & $(9)$ \\
& DE & EL & ES & FR & HU & IT & NL & PL & SE \\
Variable & Mean/SD & Mean/SD & Mean/SD & Mean/SD & Mean/SD & Mean/SD & Mean/SD & Mean/SD & Mean/SD \\
\hline \multirow{2}{*}{ Own country } & 85.175 & 83.253 & 86.077 & 86.298 & 89.096 & 84.675 & 84.594 & 82.357 & 84.681 \\
& $(30.843)$ & $(35.471)$ & $(34.440)$ & $(35.354)$ & $(35.030)$ & $(34.202)$ & $(30.831)$ & $(35.079)$ & $(36.412)$ \\
EU country & 84.099 & 81.944 & 85.175 & 85.236 & 90.077 & 86.302 & 83.705 & 81.451 & 85.224 \\
& $(31.376)$ & $(35.718)$ & $(33.992)$ & $(33.698)$ & $(32.796)$ & $(33.121)$ & $(31.136)$ & $(35.689)$ & $(35.551)$ \\
\multirow{2}{*}{ Non-EU country } & 83.168 & 80.165 & 84.970 & 85.657 & 87.994 & 83.657 & 84.277 & 82.048 & 82.777 \\
& $(32.609)$ & $(35.631)$ & $(35.692)$ & $(35.296)$ & $(34.430)$ & $(33.952)$ & $(31.546)$ & $(36.349)$ & $(36.348)$ \\
$\mathrm{N}$ & 704 & 692 & 762 & 738 & 691 & 683 & 716 & 714 & 687 \\
\hline
\end{tabular}

Notes: The table reports the average number of points and its standard deviation by country respondents in the control group have returned to the sender (Player A) as Player B in the Trust game, depending on whether the fellow player is from their own country, another EU country or from a non-EU country. 
Table A11: Dictator game: Descriptive Statistics Player A by country

\begin{tabular}{lccccccccc}
\hline & $(1)$ & $(2)$ & $(3)$ & $(4)$ & $(5)$ & $(6)$ & $(7)$ & $(8)$ & $(9)$ \\
Variable & DE & EL & ES & FR & HU & IT & NL & PL & SE \\
Mean/SD & Mean/SD & Mean/SD & Mean/SD & Mean/SD & Mean/SD & Mean/SD & Mean/SD & Mean/SD \\
\hline \multirow{2}{*}{ Own country } & 97.037 & 98.312 & 103.944 & 107.202 & 111.056 & 110.609 & 100.894 & 101.213 & 101.926 \\
& $(37.770)$ & $(46.910)$ & $(46.085)$ & $(50.805)$ & $(47.903)$ & $(49.566)$ & $(41.400)$ & $(47.945)$ & $(46.851)$ \\
EU country & 94.740 & 92.802 & 100.626 & 103.965 & 107.010 & 107.124 & 95.191 & 97.835 & 96.646 \\
& $(38.658)$ & $(44.618)$ & $(46.034)$ & $(49.862)$ & $(46.952)$ & $(49.100)$ & $(39.200)$ & $(46.314)$ & $(48.581)$ \\
Non-EU country & 92.219 & 92.263 & 99.585 & 100.551 & 103.881 & 104.823 & 95.395 & 96.947 & 94.397 \\
& $(40.077)$ & $(46.542)$ & $(45.993)$ & $(51.943)$ & $(49.625)$ & $(49.264)$ & $(42.466)$ & $(48.407)$ & $(48.960)$ \\
N & 704 & 692 & 762 & 738 & 691 & 683 & 716 & 714 & 687 \\
\hline
\end{tabular}

Notes: The table reports the average number of points and its standard deviation by country respondents in the control group have sent to the receiver (Player B) as Player A in the Dictator game, depending on whether the fellow player is from their own country, another EU country or from a non-EU country.

Table A12: Average treatment effects: Trust (Logit)

\begin{tabular}{lccc}
\hline & Own country & EU & Non EU \\
\hline & 1.000 & 0.995 & 1.019 \\
T1: COVID-19 & $(0.036)$ & $(0.036)$ & $(0.037)$ \\
& 0.978 & 1.010 & 0.957 \\
T2: EU Trade & $(0.036)$ & $(0.037)$ & $(0.035)$ \\
& 1.003 & 1.015 & 0.998 \\
T3: EU Common values & $(0.036)$ & $(0.037)$ & $(0.036)$ \\
\hline Observations & 25720 & 25720 & 25720 \\
Fixed effects: & \multicolumn{3}{c}{ Country \& date } \\
\hline
\end{tabular}

Notes: Logit models. The table displays odds ratios. Robust standard errors are in parentheses: ${ }^{*} p<0.10,{ }^{* *}$ $p<0.05,{ }^{* * *} p<0.01$. Controls: age, gender, marital status, education level, equivalized household gross income in February/July 2020, time to complete survey, total number of children and adults younger/older than 65 in the household. 
Table A13: Balancing Tests

\begin{tabular}{|c|c|c|c|}
\hline & $\begin{array}{c}\Delta \mathrm{T} 1-\text { Control } \\
\text { Diff. } / \mathrm{SE}\end{array}$ & $\begin{array}{c}\Delta \mathrm{T} 2-\text { Control } \\
\text { Diff. } / \mathrm{SE}\end{array}$ & $\begin{array}{c}\Delta \mathrm{T} 3-\text { Control } \\
\text { Diff./SE }\end{array}$ \\
\hline \multirow[t]{2}{*}{ Age } & 0.4725 & 0.2316 & 0.3277 \\
\hline & $(0.2488)$ & $(0.2494)$ & $(0.2495)$ \\
\hline \multirow[t]{2}{*}{ Female } & 0.0050 & 0.0093 & 0.0130 \\
\hline & $(0.0088)$ & $(0.0088)$ & $(0.0088)$ \\
\hline \multirow[t]{2}{*}{ Other gender } & 0.0003 & 0.0006 & -0.0000 \\
\hline & $(0.0005)$ & $(0.0006)$ & $(0.0005)$ \\
\hline \multirow[t]{2}{*}{ Secondary education } & 0.0008 & -0.0013 & -0.0044 \\
\hline & $(0.0088)$ & $(0.0089)$ & $(0.0088)$ \\
\hline \multirow[t]{2}{*}{ Tertiary education } & -0.0015 & -0.0031 & 0.0042 \\
\hline & $(0.0088)$ & $(0.0088)$ & $(0.0088)$ \\
\hline \multirow[t]{2}{*}{ Single } & $-0.0196^{* *}$ & -0.0082 & -0.0087 \\
\hline & $(0.0085)$ & $(0.0086)$ & $(0.0086)$ \\
\hline \multirow[t]{2}{*}{$\mathrm{N}^{\circ}$ adults above 65 in the household } & 0.0054 & -0.0008 & 0.0061 \\
\hline & $(0.0116)$ & $(0.0116)$ & $(0.0114)$ \\
\hline \multirow[t]{2}{*}{$\mathrm{N}^{\circ}$ adults below 65 in the household } & $-0.0310^{*}$ & 0.0124 & -0.0049 \\
\hline & $(0.0183)$ & $(0.0187)$ & $(0.0185)$ \\
\hline \multirow[t]{2}{*}{$\mathrm{N}^{\circ}$ children in the household } & -0.0052 & -0.0019 & -0.0194 \\
\hline & $(0.0145)$ & $(0.0148)$ & $(0.0143)$ \\
\hline \multirow[t]{2}{*}{ Hh. Equivalized Gross Income Quintile (Feb. 2020) } & 0.0285 & -0.0176 & 0.0195 \\
\hline & $(0.0248)$ & $(0.0250)$ & $(0.0250)$ \\
\hline \multirow[t]{2}{*}{ Hh. Equivalized Gross Income Quintile (July 2020) } & 0.0308 & -0.0146 & 0.0328 \\
\hline & $(0.0248)$ & $(0.0250)$ & $(0.0249)$ \\
\hline \multirow[t]{2}{*}{ COVID-19 regional incidence } & 2.9309 & -5.7763 & -2.3829 \\
\hline & $(5.7535)$ & $(5.7402)$ & $(5.7205)$ \\
\hline \multirow[t]{2}{*}{ EU identity } & 0.0163 & 0.0203 & 0.0618 \\
\hline & $(0.0513)$ & $(0.0510)$ & $(0.0509)$ \\
\hline \multirow[t]{2}{*}{ Political orientation } & 0.0499 & 0.0308 & 0.0182 \\
\hline & $(0.0424)$ & $(0.0426)$ & $(0.0427)$ \\
\hline \multirow[t]{2}{*}{ Economic effect of COVID-19 } & 0.0142 & 0.0232 & 0.0005 \\
\hline & $(0.0169)$ & $(0.0170)$ & $(0.0168)$ \\
\hline \multirow[t]{2}{*}{ Time to complete the survey } & 0.1040 & $-0.5504^{* *}$ & -0.0612 \\
\hline & $(0.2632)$ & $(0.2574)$ & $(0.2680)$ \\
\hline
\end{tabular}


Table A14: Average treatment effects: EU identity and Political orientation

\begin{tabular}{lcc}
\hline & EU Identity & Political orientation \\
\hline T1: COVID-19 & 0.014 & 0.045 \\
& $(0.049)$ & $(0.042)$ \\
T2: EU Trade & 0.023 & 0.029 \\
& $(0.049)$ & $(0.042)$ \\
T3: EU Common values & 0.046 & 0.023 \\
& $(0.049)$ & $(0.042)$ \\
\hline Observations & 25720 & 25720 \\
$R^{2}$ & 0.084 & 0.041 \\
Fixed effects: & \multicolumn{2}{c}{ Country \& date } \\
\hline
\end{tabular}

Notes: OLS model. Robust standard errors are in parentheses: ${ }^{*} p<0.10,{ }^{* *} p<0.05,{ }^{* * *} p<0.01$. Controls: age, gender, marital status, education level, equivalized household gross income in February/July 2020, time to complete survey, total number of children and adults younger/older than 65 in the household. 
Table A15: Heterogeneity analysis - Trust

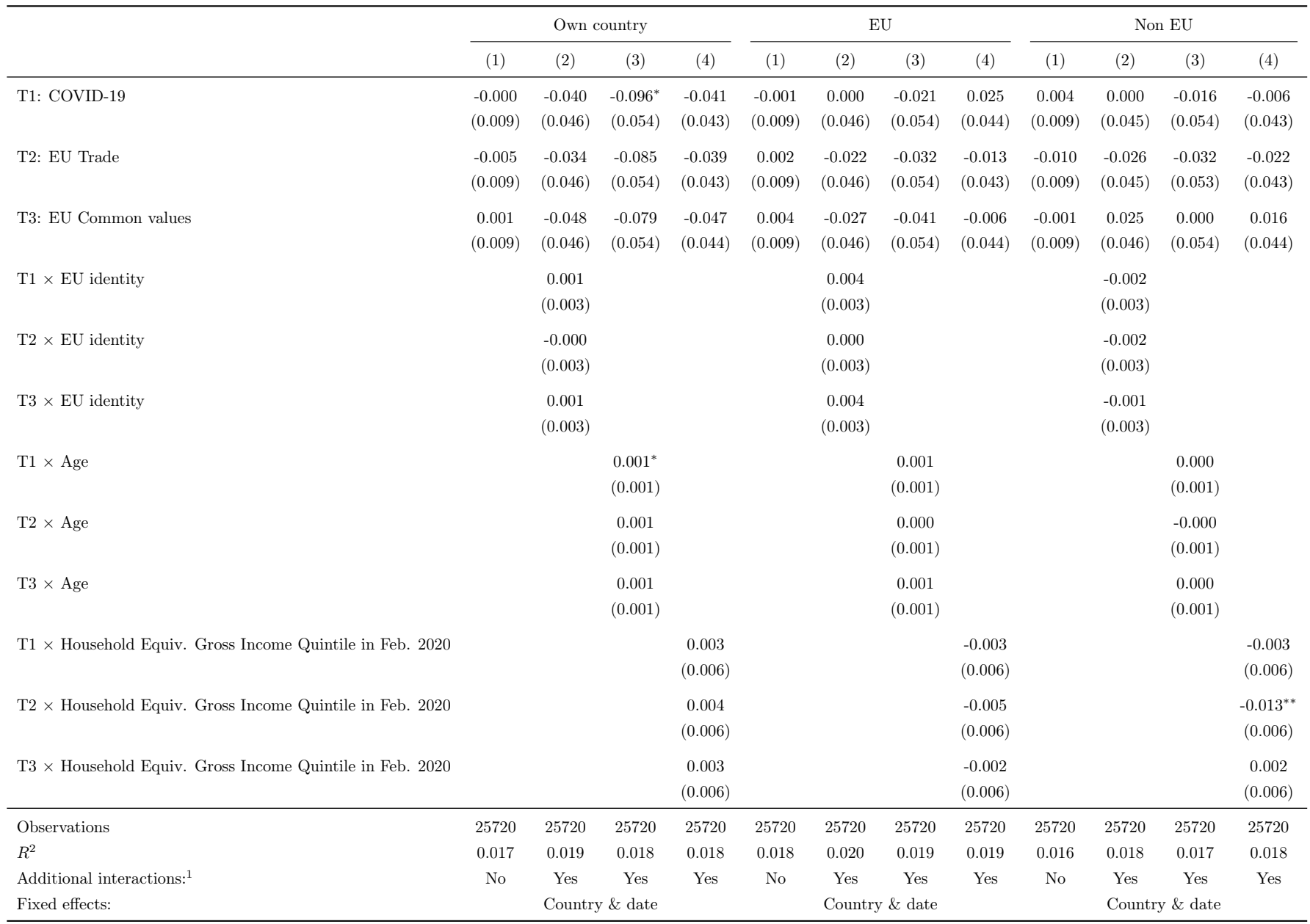

Notes: OLS model. Robust standard errors are in parentheses: ${ }^{*} p<0.10,{ }^{* *} p<0.05,{ }^{* * *} p<0.01$. Controls: age, gender, marital status, education level, equivalized household gross income in February/July 2020, time to complete survey, total number of children and adults younger/older than 65 in the household and the interacted variable. ${ }^{1}$ The OLS regressions also include interactions between the treatment dummies and country dummies, education, and gender, respectively. 
Table A16: Heterogeneity analysis - Reciprocity

\begin{tabular}{|c|c|c|c|c|c|c|c|c|c|c|c|c|}
\hline & \multicolumn{4}{|c|}{ Own country } & \multicolumn{4}{|c|}{$\mathrm{EU}$} & \multicolumn{4}{|c|}{ Non EU } \\
\hline & (1) & (2) & (3) & (4) & (1) & $(2)$ & $(3)$ & (4) & (1) & (2) & (3) & (4) \\
\hline T1: COVID-19 & $\begin{array}{c}2.108^{* * *} \\
(0.609)\end{array}$ & $\begin{array}{c}1.965 \\
(3.337)\end{array}$ & $\begin{array}{c}0.920 \\
(3.885)\end{array}$ & $\begin{array}{c}1.281 \\
(3.153)\end{array}$ & $\begin{array}{l}1.049^{*} \\
(0.604)\end{array}$ & $\begin{array}{c}5.027 \\
(3.355)\end{array}$ & $\begin{array}{c}5.740 \\
(3.887)\end{array}$ & $\begin{array}{c}4.910 \\
(3.179)\end{array}$ & $\begin{array}{l}1.318^{* *} \\
(0.618)\end{array}$ & $\begin{array}{c}0.947 \\
(3.397)\end{array}$ & $\begin{array}{c}4.161 \\
(3.954)\end{array}$ & $\begin{array}{c}2.560 \\
(3.197)\end{array}$ \\
\hline T2: EU Trade & $\begin{array}{l}1.142^{*} \\
(0.602)\end{array}$ & $\begin{array}{l}-2.886 \\
(3.317)\end{array}$ & $\begin{array}{l}-5.569 \\
(3.874)\end{array}$ & $\begin{array}{l}-4.697 \\
(3.132)\end{array}$ & $\begin{array}{c}0.157 \\
(0.599)\end{array}$ & $\begin{array}{l}-0.895 \\
(3.380)\end{array}$ & $\begin{array}{l}-0.183 \\
(3.879)\end{array}$ & $\begin{array}{l}-2.119 \\
(3.195)\end{array}$ & $\begin{array}{l}-0.072 \\
(0.614)\end{array}$ & $\begin{array}{l}-4.569 \\
(3.427)\end{array}$ & $\begin{array}{c}1.135 \\
(3.971)\end{array}$ & $\begin{array}{l}-2.301 \\
(3.226)\end{array}$ \\
\hline T3: EU Common values & $\begin{array}{c}2.212^{* * *} \\
(0.595)\end{array}$ & $\begin{array}{c}0.897 \\
(3.373)\end{array}$ & $\begin{array}{l}-2.279 \\
(3.943)\end{array}$ & $\begin{array}{l}-0.735 \\
(3.201)\end{array}$ & $\begin{array}{l}1.410^{* *} \\
(0.590)\end{array}$ & $\begin{array}{l}-0.288 \\
(3.356)\end{array}$ & $\begin{array}{c}0.803 \\
(3.887)\end{array}$ & $\begin{array}{l}-1.819 \\
(3.178)\end{array}$ & $\begin{array}{c}0.798 \\
(0.607)\end{array}$ & $\begin{array}{l}-2.891 \\
(3.415)\end{array}$ & $\begin{array}{c}0.487 \\
(3.980)\end{array}$ & $\begin{array}{l}-2.445 \\
(3.228)\end{array}$ \\
\hline $\mathrm{T} 1 \times$ EU identity & & $\begin{array}{l}-0.118 \\
(0.230)\end{array}$ & & & & $\begin{array}{l}-0.159 \\
(0.225)\end{array}$ & & & & $\begin{array}{c}0.214 \\
(0.232)\end{array}$ & & \\
\hline $\mathrm{T} 2 \times$ EU identity & & $\begin{array}{l}-0.277 \\
(0.230)\end{array}$ & & & & $\begin{array}{l}-0.285 \\
(0.227)\end{array}$ & & & & $\begin{array}{c}0.375 \\
(0.234)\end{array}$ & & \\
\hline T3 $\times$ EU identity & & $\begin{array}{l}-0.289 \\
(0.226)\end{array}$ & & & & $\begin{array}{l}-0.298 \\
(0.222)\end{array}$ & & & & $\begin{array}{c}0.070 \\
(0.230)\end{array}$ & & \\
\hline T1 $\times$ Age & & & $\begin{array}{c}0.009 \\
(0.045)\end{array}$ & & & & $\begin{array}{l}-0.031 \\
(0.045)\end{array}$ & & & & $\begin{array}{l}-0.041 \\
(0.046)\end{array}$ & \\
\hline $\mathrm{T} 2 \times$ Age & & & $\begin{array}{c}0.025 \\
(0.045)\end{array}$ & & & & $\begin{array}{l}-0.040 \\
(0.045)\end{array}$ & & & & $\begin{array}{l}-0.067 \\
(0.046)\end{array}$ & \\
\hline T3 $\times$ Age & & & $\begin{array}{c}0.032 \\
(0.045)\end{array}$ & & & & $\begin{array}{l}-0.054 \\
(0.045)\end{array}$ & & & & $\begin{array}{l}-0.060 \\
(0.046)\end{array}$ & \\
\hline T1 × Household Equiv. Gross Income Quintile in Feb. 2020 & & & & $\begin{array}{c}0.059 \\
(0.449)\end{array}$ & & & & $\begin{array}{l}-0.540 \\
(0.446)\end{array}$ & & & & $\begin{array}{l}-0.354 \\
(0.456)\end{array}$ \\
\hline T2 $\times$ Household Equiv. Gross Income Quintile in Feb. 2020 & & & & $\begin{array}{c}0.318 \\
(0.446)\end{array}$ & & & & $\begin{array}{l}-0.081 \\
(0.442)\end{array}$ & & & & $\begin{array}{c}0.031 \\
(0.454)\end{array}$ \\
\hline T3 $\times$ Household Equiv. Gross Income Quintile in Feb. 2020 & & & & $\begin{array}{c}0.067 \\
(0.439)\end{array}$ & & & & $\begin{array}{l}-0.109 \\
(0.435)\end{array}$ & & & & $\begin{array}{l}-0.120 \\
(0.444)\end{array}$ \\
\hline Observations & 25720 & 25720 & 25720 & 25720 & 25720 & 25720 & 25720 & 25720 & 25720 & 25720 & 25720 & 25720 \\
\hline$R^{2}$ & 0.010 & 0.013 & 0.013 & 0.013 & 0.011 & 0.015 & 0.013 & 0.013 & 0.010 & 0.013 & 0.012 & 0.012 \\
\hline Additional interactions: ${ }^{1}$ & No & Yes & Yes & Yes & No & Yes & Yes & Yes & No & Yes & Yes & Yes \\
\hline Fixed effects: & & Country & $\&$ date & & & Country & $\&$ date & & & Country & $\&$ date & \\
\hline
\end{tabular}

Notes: OLS model. Robust standard errors are in parentheses: ${ }^{*} p<0.10,{ }^{* *} p<0.05$, ${ }^{* * *} p<0.01$. Controls: age, gender, marital status, education level, equivalized household gross income in February/July 2020, time to complete survey, total number of children and adults younger/older than 65 in the household and the interacted variable. ${ }^{1}$ The OLS regressions also include interactions between the treatment dummies and country dummies, education, and gender, respectively. 
Table A17: Heterogeneity analysis - Altruism

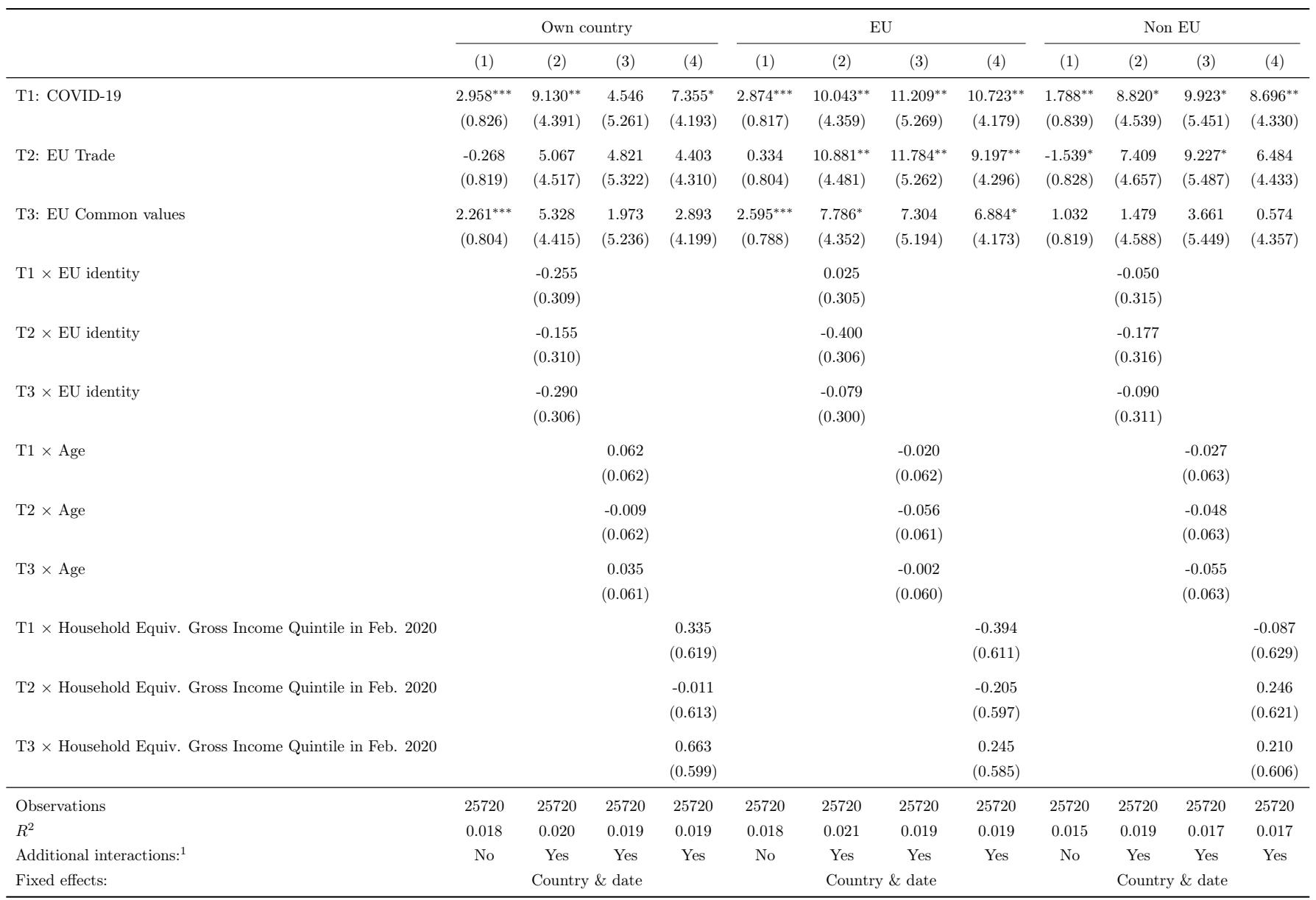

Notes: OLS model. Robust standard errors are in parentheses: ${ }^{*} p<0.10,{ }^{* *} p<0.05,{ }^{* * *} p<0.01$. Controls: age, gender, marital status, education level, equivalized household gross income in February/July 2020, time to complete survey, total number of children and adults younger/older than 65 in the household and the interacted variable. ${ }^{1}$ The OLS regressions also include interactions between the treatment dummies and country dummies, education, and gender, respectively. 


\section{B Appendix Figures}

Figure A1: Outcome: Trust

COVID-19 treatment

(a) Own country

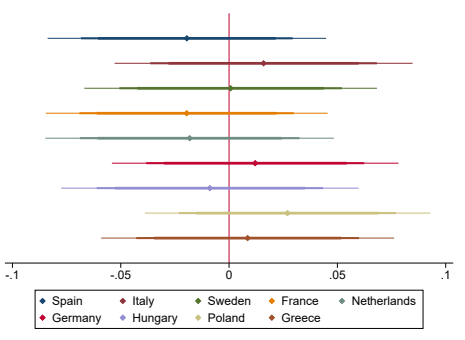

(d) Own country

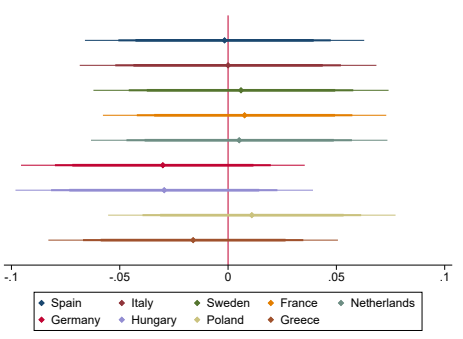

(b) EU

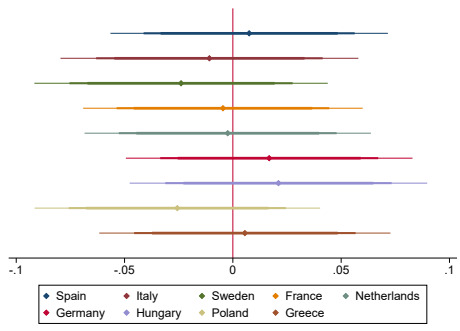

Trade treatment

(c) Non EU

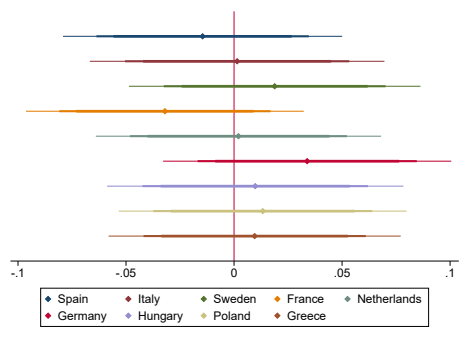

(f) Non EU
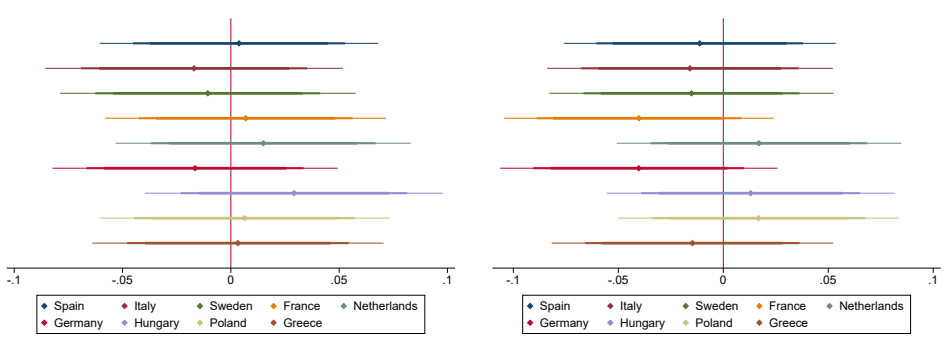

EU Common values treatment

(g) Own country

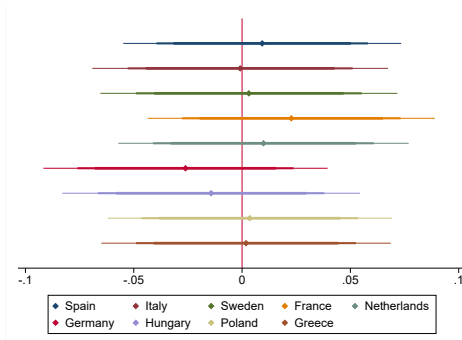

(h) EU

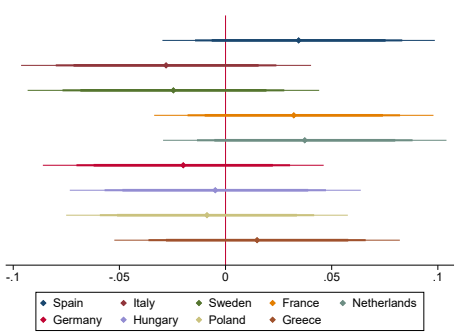

(i) Non EU

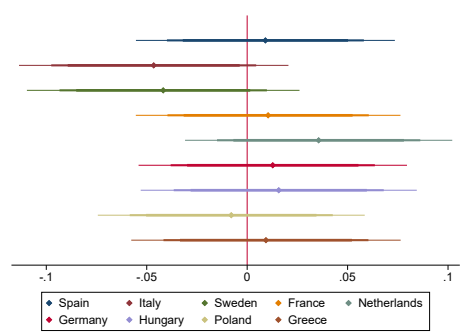

Notes: The figures show average treatment effects by country. Controls: age group dummies, gender, marital status, education level, equivalized household gross income group dummies in February/July 2020, time to complete survey, total number of children and adults younger/older than 65 in the household. 
Figure A2: Outcome: Reciprocity

COVID-19 treatment

(a) Own country

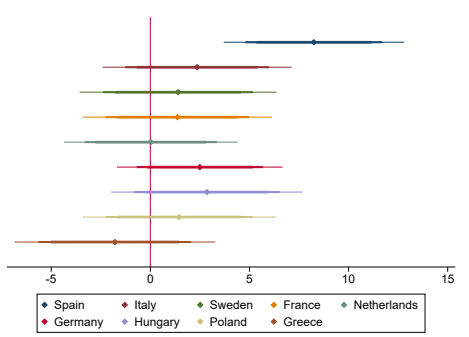

(d) Own country

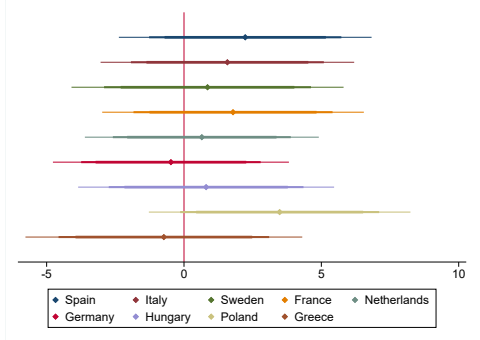

(b) EU

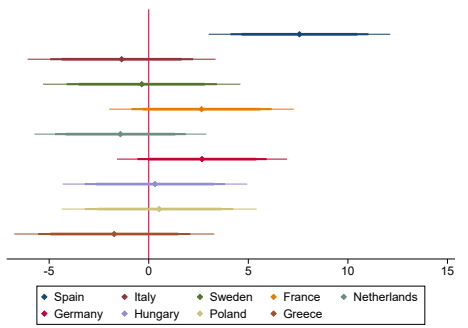

Trade treatment

(e) EU

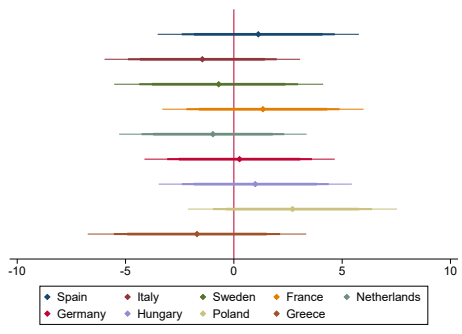

(c) Non EU

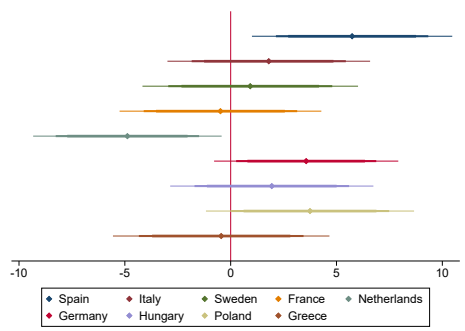

(f) Non EU

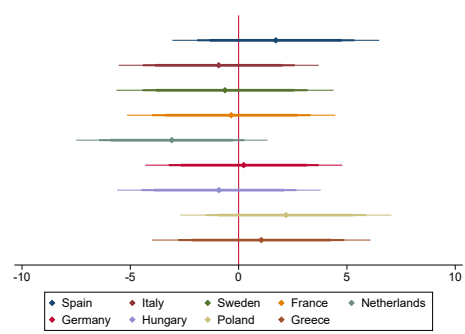

\section{EU Common values treatment}

(g) Own country

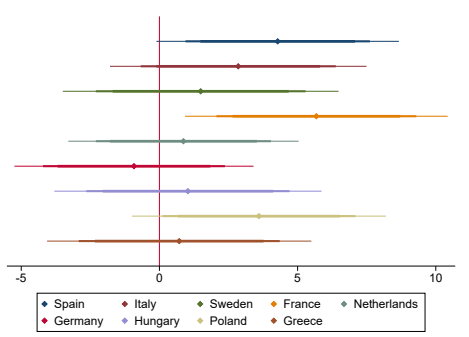

(h) EU

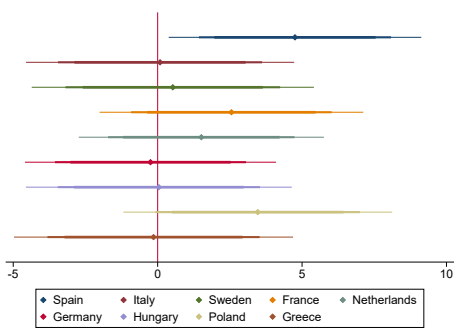

(i) Non EU

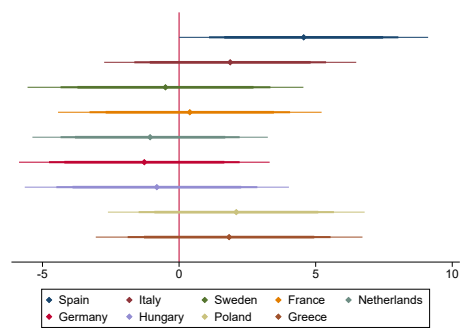

Notes: The figures show average treatment effects by country. Controls: age group dummies, gender, marital status, education level, equivalized household gross income group dummies in February/July 2020, time to complete survey, total number of children and adults younger/older than 65 in the household. 
Figure A3: Outcome: Altruism

COVID-19 treatment

(a) Own country

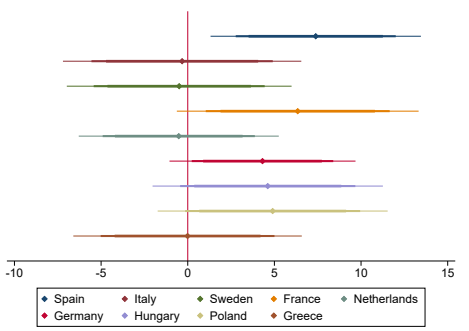

(d) Own country

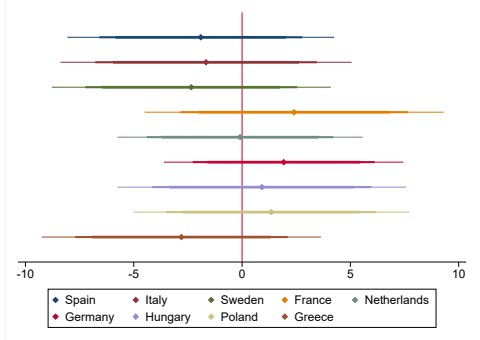

(b) EU

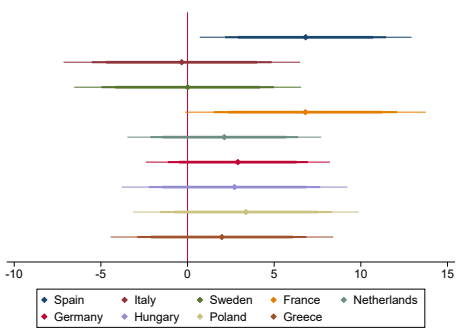

Trade treatment

(e) EU

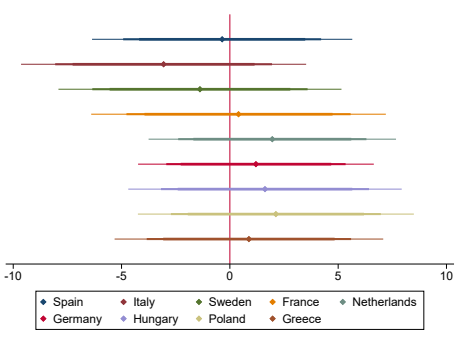

(c) Non EU

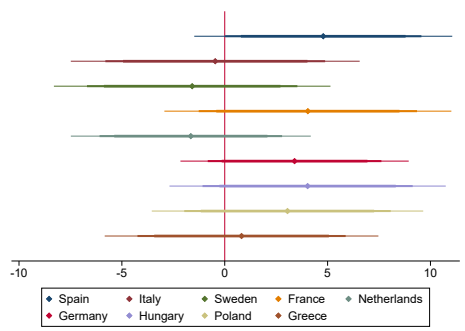

(f) Non EU

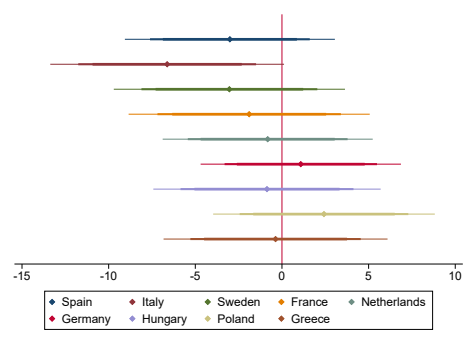

\section{EU Common values treatment}

(g) Own country

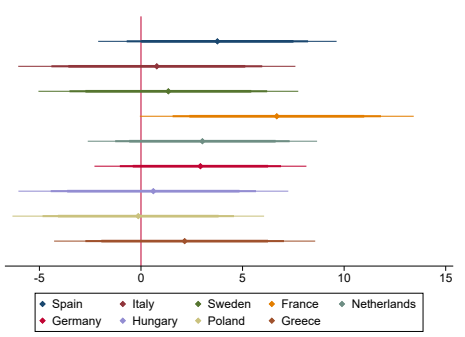

(h) EU

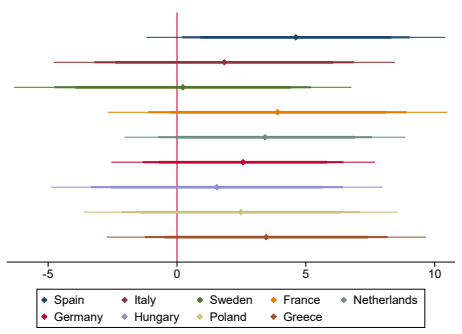

(i) Non EU

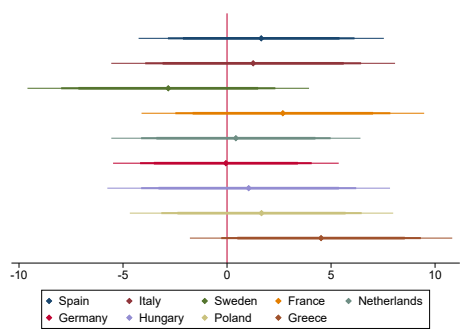

Notes: The figures show average treatment effects by country. Controls: age group dummies, gender, marital status, education level, equivalized household gross income group dummies in February/July 2020, time to complete survey, total number of children and adults younger/older than 65 in the household. 
Figure A4: Variable importance: COVID-19 treatment, Summary Index

(a) Own country

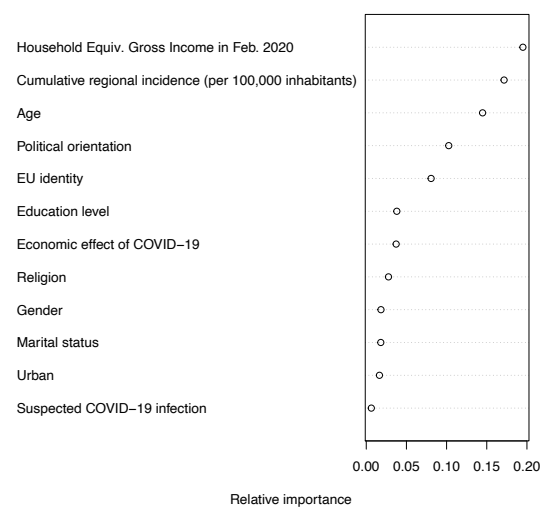

(b) EU

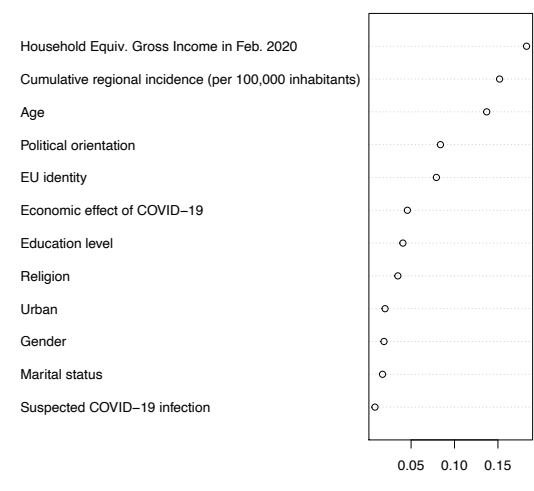

(c) Non EU

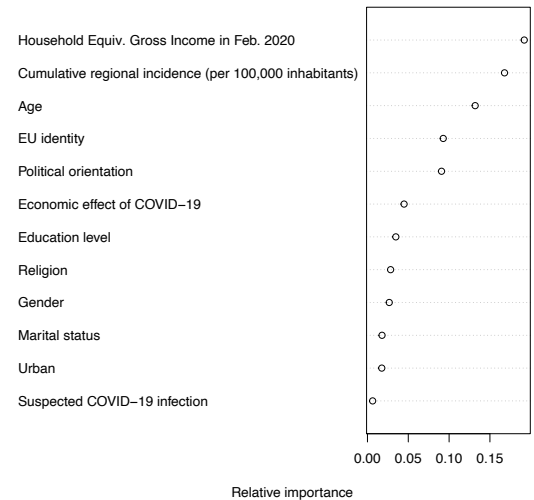

Variable importance for the three outcomes in the game, using a generalized random forest framework ( $N=20.000$ trees). The variable importance plot provides a simple weighted sum of how many times a feature was split at each depth in the forest. 
Figure A5: Variable importance: Trade treatment, Summary Index
(a) Own country
(b) EU
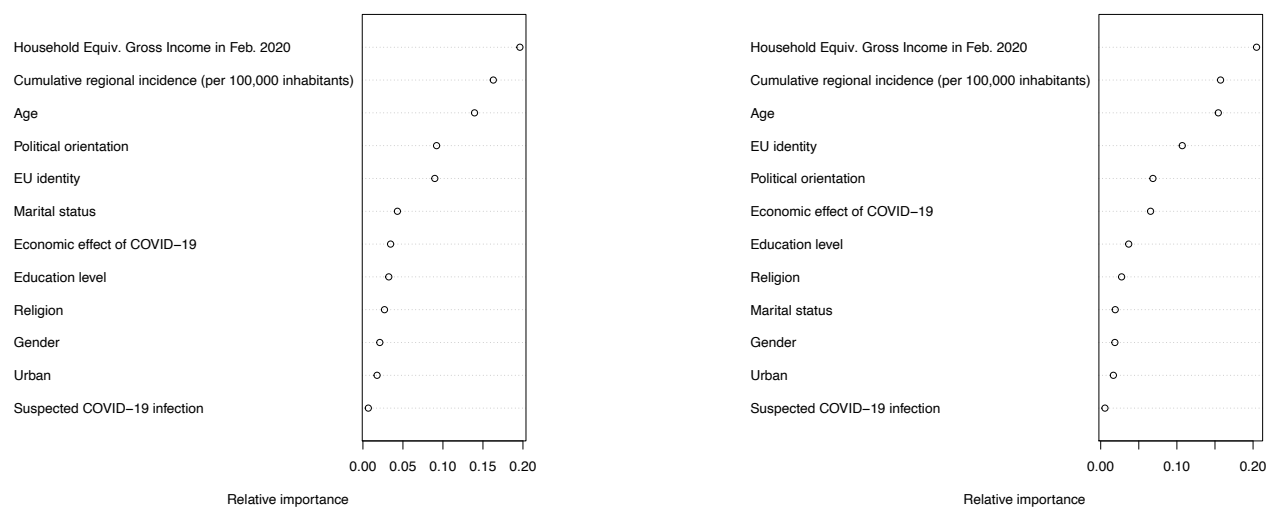

(c) Non EU

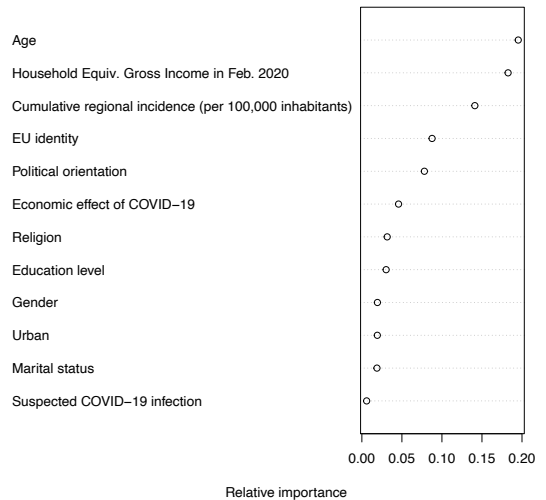

Variable importance for the three outcomes in the game, using a generalized random forest framework ( $N=20.000$ trees). The variable importance plot provides a simple weighted sum of how many times a feature was split at each depth in the forest. 
Figure A6: Variable importance: EU Common values treatment, Summary Index

(a) Own country

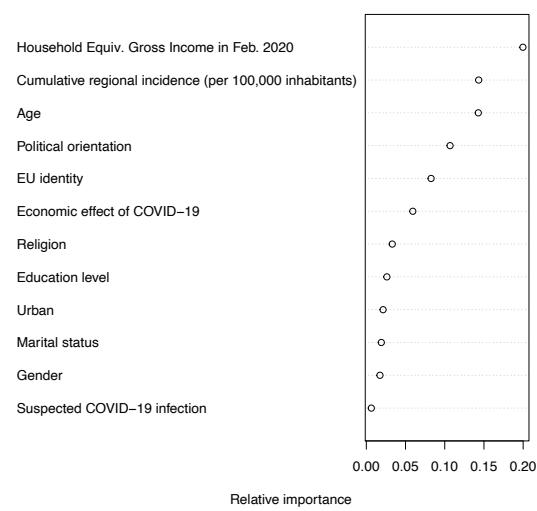

(b) EU

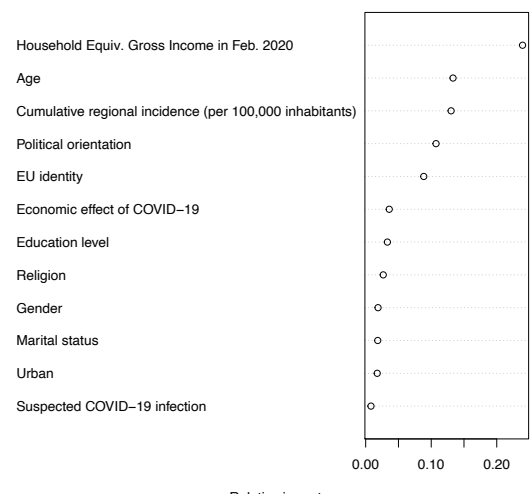

(c) Non EU

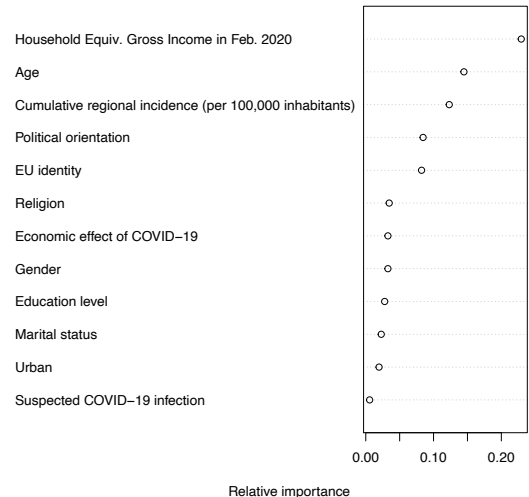

Variable importance for the three outcomes in the game, using a generalized random forest framework $(N=20.000$ trees). The variable importance plot provides a simple weighted sum of how many times a feature was split at each depth in the forest. 
Figure A7: Outcome: Trust - Excluding one country at a time

\section{COVID-19 treatment}

(a) Own country

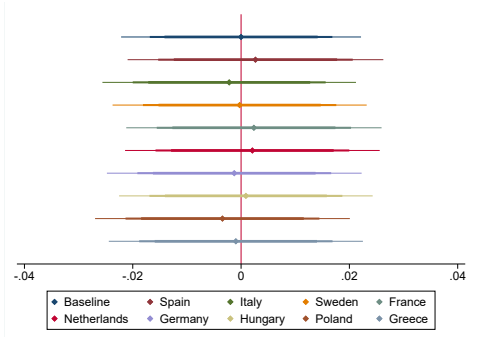

(d) Own country

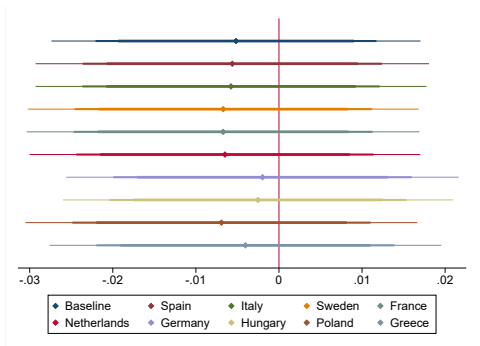

(b) EU

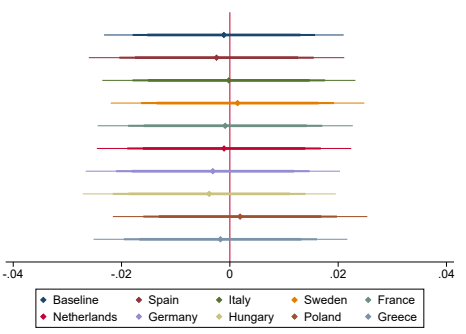

Trade treatment

(c) Non EU

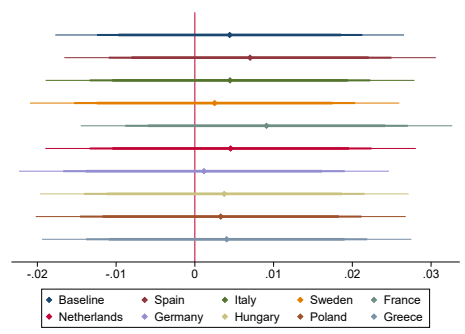

(f) Non EU
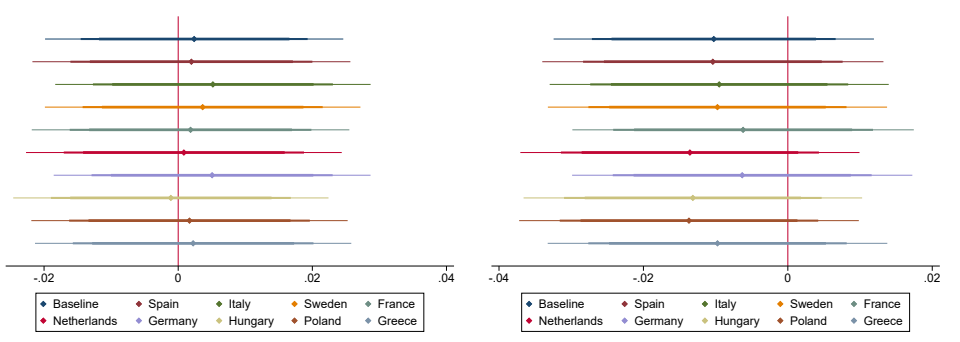

\section{EU Common values treatment}

(g) Own country

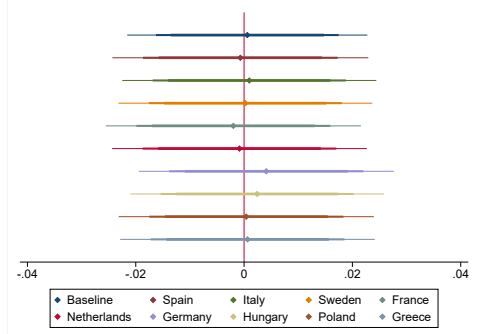

(h) EU

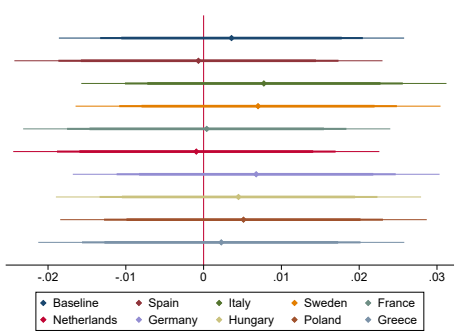

(i) Non EU

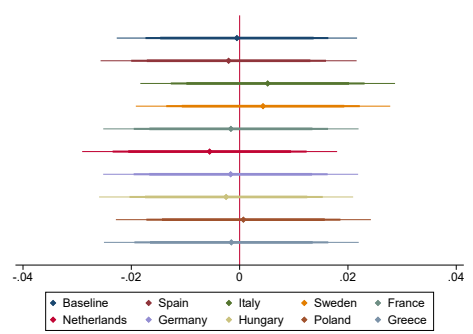

Notes: The figures show average treatment effects for the full sample and for samples where one country at a time is excluded. For example, the treatment effect labeled "Germany" is based on a sample which includes eight out of nine EU countries, with Germany being excluded. Controls: age, gender, marital status, education level, equivalized household gross income quintile in February/July 2020, time to complete survey, total number of children and adults younger/older than 65 in the household. 
Figure A8: Outcome: Reciprocity - Excluding one country at a time

\section{COVID-19 treatment}

(a) Own country

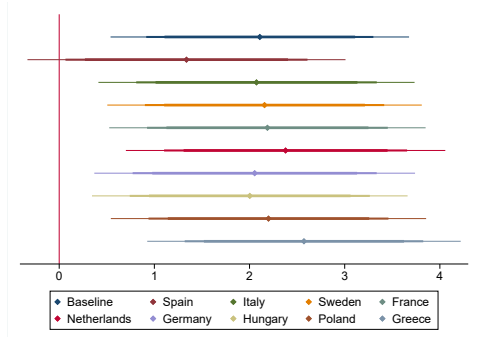

(d) Own country

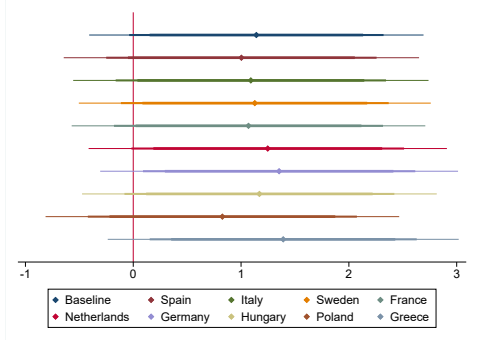

(b) EU

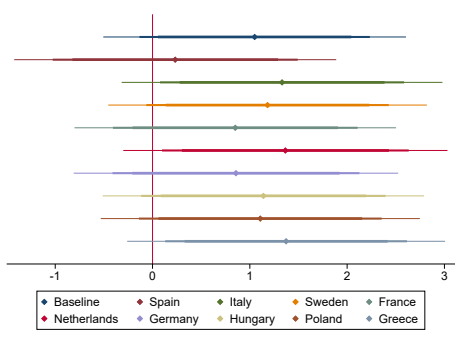

Trade treatment

(c) Non EU

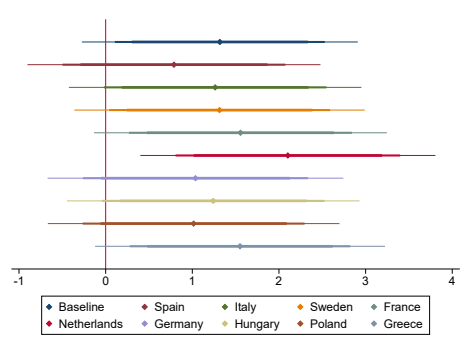

(f) Non EU

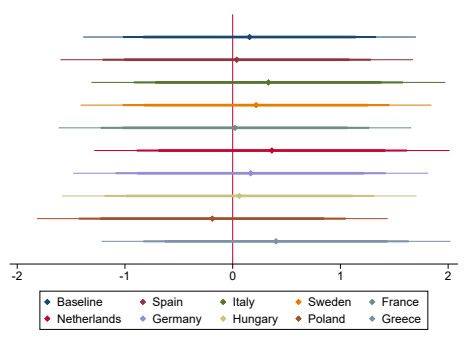

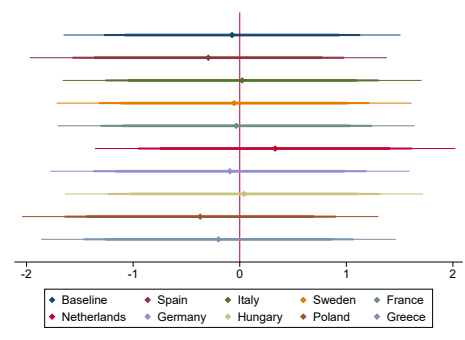

\section{EU Common values treatment}

(g) Own country

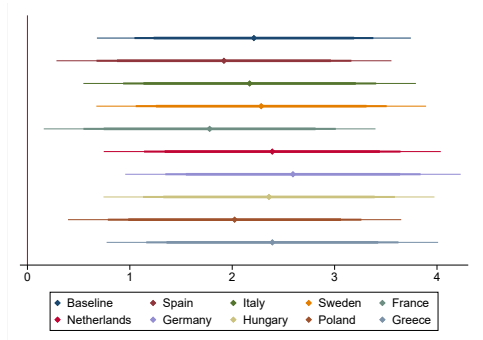

(h) EU

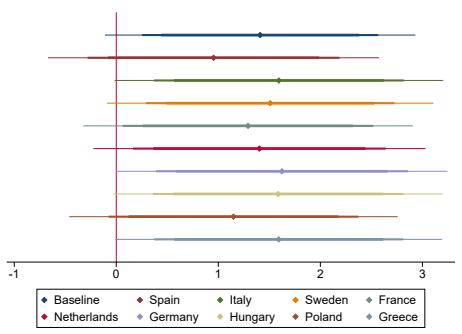

(i) Non EU

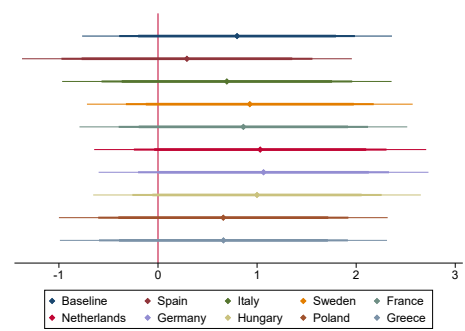

Notes: The figures show average treatment effects for the full sample and for samples where one country at a time is excluded. For example, the treatment effect labeled "Germany" is based on a sample which includes eight out of nine EU countries, with Germany being excluded. Controls: age, gender, marital status, education level, equivalized household gross income quintile in February/July 2020, time to complete survey, total number of children and adults younger/older than 65 in the household. 
Figure A9: Outcome: Altruism - Excluding one country at a time

COVID-19 treatment

(a) Own country

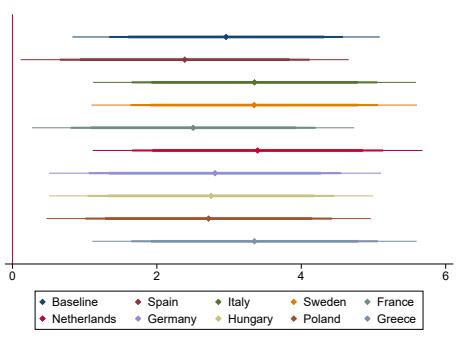

(d) Own country

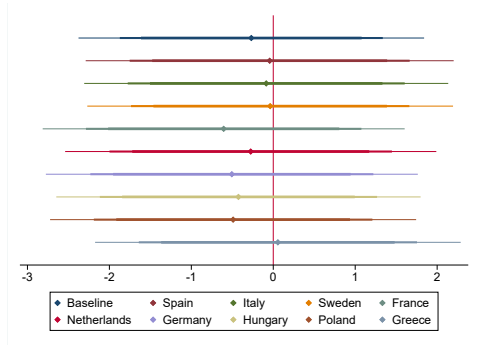

(b) EU

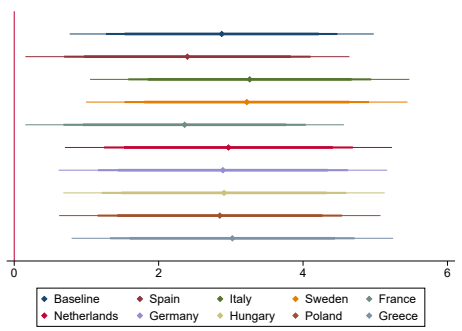

Trade treatment

(c) Non EU

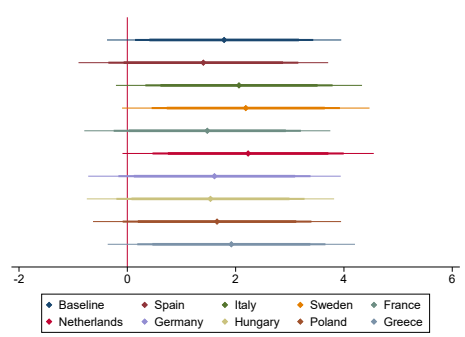

(f) Non EU
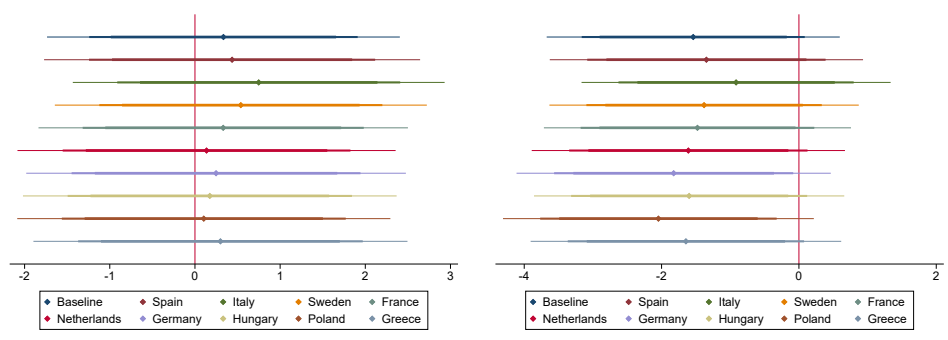

\section{EU Common values treatment}

(g) Own country

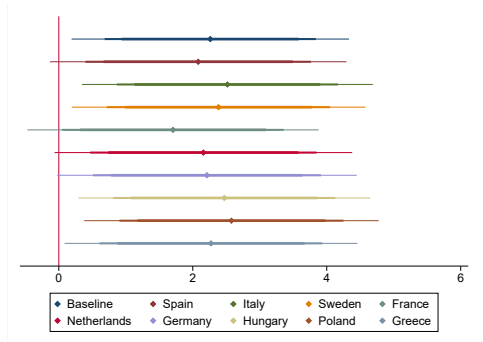

(h) EU

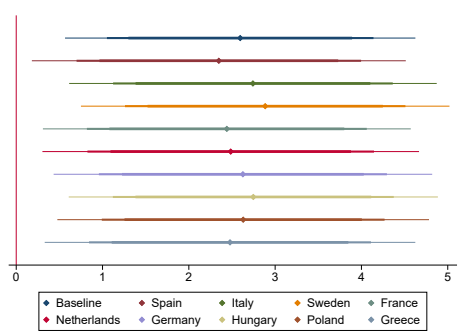

(i) Non EU

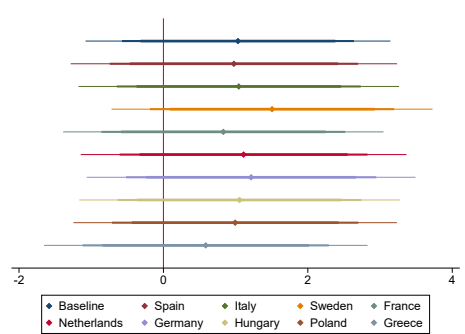

Notes: The figures show average treatment effects for the full sample and for samples where one country at a time is excluded. For example, the treatment effect labeled "Germany" is based on a sample which includes eight out of nine EU countries, with Germany being excluded. Controls: age, gender, marital status, education level, equivalized household gross income quintile in February/July 2020, time to complete survey, total number of children and adults younger/older than 65 in the household. 